\title{
Relationship Lending and the Transmission of Monetary Policy
}

\author{
Kinda Hachem*† \\ University of Toronto
}

First Version September 2008; This Version January 2011

\begin{abstract}
Repeated interactions allow lenders to uncover private information about their clients, decreasing the informational asymmetry between a borrower and his lender but introducing one between the lender and competing financiers. This paper constructs a credit-based model of production to analyze how learning through lending relationships affects the monetary transmission mechanism. I examine how monetary policy changes the incentives of borrowers and lenders to engage in relationship lending and how these changes then shape the response of aggregate output. A central finding is that relationship lending induces a smoother steady state output profile and a less volatile response to certain monetary shocks. This result provides a theoretical basis for cross-country transmission differences via a relationship lending channel.

Keywords: Relationship Lending, Monetary Transmission, Credit Channels

JEL classification: D82, D83, E37, E44

*Department of Economics, University of Toronto, 150 St. George Street, Toronto, Ontario, Canada, M5S 3G7. E-mail: kinda.hachem@utoronto.ca.

${ }^{\dagger}$ This paper is based on the first chapter of my dissertation at the University of Toronto. I thank Shouyong Shi for invaluable guidance and supervision. I also thank the associate editor, an anonymous referee, and seminar participants at the University of Toronto, the Federal Reserve Bank of Chicago, and the 2010 SED Annual Meeting for helpful suggestions. Financial support from the Social Sciences and Humanities Research Council of Canada as well as Shouyong Shi's Bank of Canada Fellowship and Canada Research Chair are gratefully acknowledged. Any remaining errors are my own.
\end{abstract}




\section{Introduction}

Macroeconomists have shown how intermediation costs can propagate shocks when lenders are imperfectly informed about their borrowers. Commonly omitted from the analysis though is the potential for lenders to learn about their clients through repeated interactions. This omission is problematic because recent empirical evidence suggests that there is a link between relationship lending and the transmission of monetary shocks. As defined in Boot (2000), relationship lending is the provision of credit by intermediaries that acquire proprietary information about their borrowers over time or across products. Among the major European economies, Ehrmann et al (2001) establish that relationship lending is much more prevalent in Germany and Italy than in Spain and France. Incidentally, they also find that the quantity of bank loans responds less severely to a monetary contraction in the first two countries. Borio and Fritz (1995) find a similar pattern on the pricing side, with the passthrough from higher policy rates to higher loan rates occurring more slowly in Germany and Italy than in Spain. ${ }^{1}$ A correlation with spending is also visible as Mojon and Peersman (2003) demonstrate that the peak decline in investment following a monetary contraction is smaller in Germany and Italy than in Spain and France.

In this paper, I establish a theory of how relationship lending affects the macroeconomic response to monetary policy. I begin by constructing a credit-based model of production where lenders can uncover private information about their borrowers' abilities over time. While such learning decreases the informational asymmetry between a lender and his borrower, it introduces one between the lender and competing financiers so the extent and effect of relationship lending must be endogenously determined. I undertake this determination and analyze how monetary policy changes the incentives of borrowers and lenders to engage in such relationships by changing the cost of funds on the interbank market. I then examine

\footnotetext{
${ }^{1}$ Additional support for the impact of relationship lending is provided for Italy by Gambacorta (2004) and for Germany by Weth (2002) and Iacoviello and Minetti (2008). Moreover, based on U.S. survey data, Berger and Udell (1995) conclude that American borrowers with larger banking relationships tend to pay lower interest rates and are less likely to pledge collateral.
} 
how the response of aggregate output depends on the response of relationship lending. In contrast to many models of financial acceleration, I show that relationship lending prevails in equilibrium and dampens the canonical credit channel. The prevalence of such relationships depends not only on the policy rate but also on institutional parameters so, given differences in these parameters, cross-country differences in relationship lending and monetary transmission are supported.

The analysis uncovers two mechanisms through which relationship lending affects monetary transmission. The first mechanism operates during the credit relationship while the second operates beforehand. As lenders acquire information over the course of their relationships, they retain only sufficiently good borrowers. The presence of other lenders limits monopoly power and, in order to induce higher repayment rates, it is optimal for informed lenders to concede positive surplus to some of their borrowers. I demonstrate that this concession includes offering policy-invariant credit terms over intermediate ranges of the policy rate, giving rise to a first mechanism. To be sure, informed lenders do not concede the entire surplus from relationship lending and, in anticipation of future relationship profits, unmatched lenders compete more intensely for new borrowers. A second mechanism arises because this competition lowers loan rates for any given policy, alleviating some of the tightness that information frictions may impart on first-time borrowers without actually changing these frictions in the current period. At an aggregate level, the two mechanisms combine to produce a smoother steady state output profile and a less volatile response to certain monetary shocks.

The importance of financial intermediation for real activity has been emphasized in the macroeconomics literature. ${ }^{2}$ However, in analyzing how credit markets transmit shocks to the real economy, this literature has essentially discounted the propensity of agents in these markets to engage in relationship lending: Williamson (1987), Bernanke and Gertler

\footnotetext{
${ }^{2}$ Perhaps most pointedly, Bernanke (1983) and Diamond and Dybvig (1983) argue that financial disruption propelled a potentially normal-course recession into the Great Depression. For a survey of the literature on real-financial interactions in business cycles, see Gertler (1988). For a discussion of real-financial interactions in economic development, see King and Levine (1993).
} 
(1989), and Kiyotaki and Moore (1997) abstract from multi-period credit relationships while Gertler (1992), Khan and Ravikumar (2001), and Smith and Wang (2006) abstract from the learning benefits of such relationships. In contrast, the key feature of multi-period lending relationships in my model is learning and, in particular, the informational advantage of an inside lender over all other lenders. I further assume that agents cannot commit ex ante to long-term contracts, making multi-period lending relationships a sequence of one-period arrangements whose benefits are derived solely from the possibility of lender learning. ${ }^{3}$ To the extent that I emphasize relationship lending, this paper is also related to the banking literature and, in particular, work by Schmeits (2005) and Van Tassel (2002) on the properties of these relationships. However, neither of these studies investigates how policy rates affect the resulting contracts or how these contracts then transmit shocks to the macroeconomy, two questions which are key components of my analysis. ${ }^{4}$

The rest of the paper proceeds as follows: Section 2 describes the environment in more detail, Section 3 characterizes the optimal credit decisions, Section 4 determines the resulting output functions, Sections 5 and 6 discuss the output implications of relationship lending, and Section 7 concludes. All proofs and derivations are presented in the Appendix.

\section{Environment}

Time is discrete. All agents are infinitely-lived, risk neutral, and have discount factor $\beta \in$ $(0,1)$. There is a continuum of firm types, denoted by $\omega$ and distributed over the interval $[0,1]$ according to a non-degenerate probability density function $f(\cdot)$. All firms have access to the same production technologies: an investment project called $P 1$ and a speculative

\footnotetext{
${ }^{3}$ Multiple periods are important here both because they permit learning and because learning has longterm implications. This contrasts with the growth model of Bose and Cothren (1997) where lenders invest in learning about borrowers but the information acquired cannot be used in future contracts since agents are two-period-lived overlapping generations who only enter into credit contracts in their first period.

${ }^{4}$ To this end, I also extend the oft-used two-type banking environment to a continuum of borrower types, permitting non-degenerate lender beliefs and continuous output functions. Moreover, the first period credit market in my model is competitive, borrowers can choose a different project each period, and all lenders can condition their second period loan rates on first period default history. While some of the last three features are present in either Schmeits (2005) or Van Tassel (2002), neither paper contains all three. Combining these elements allows me to explore more avenues through which relationship lending can influence real activity.
} 
project called P2. Types are private information and high- $\omega$ firms are better in the sense that they are more likely to operate the investment project successfully. In particular, a type $\omega$ who operates $P 1$ is able to produce $\theta_{1}$ units of output with probability $p(\omega)$ and zero units with probability $1-p(\omega)$, where $p:[0,1] \rightarrow[0,1]$ is a continuously differentiable and strictly increasing function. In contrast, the outcome of the speculative project $P^{2}$ is independent of firm type, yielding $\theta_{2}$ with probability $q$ and zero with probability $1-q$. Assume $\theta_{2}>\theta_{1}$ and $q \theta_{2}=p(0) \theta_{1}$ so that the speculative project is riskier in the sense that it is second order stochastically dominated by the investment project. ${ }^{5}$ The presence of a speculative outside option allows the credit contracts described below to affect real activity by changing the relative attractiveness of safe projects.

To undertake either project, firms need one unit of capital. Project output is not storable so this capital must be borrowed from a measure of ex ante identical lenders that also populates the economy. Lenders cannot operate the production technologies but they have access to an interbank market for capital. The interest rate in the interbank market is denoted by $r$. It is affected by central bank monetary policy and enters the model as the lenders' cost of funds. ${ }^{6}$ To simplify the analysis, I assume that $r$ is exogenous and refer to it directly as the policy rate.

Lenders also have an ability to learn about the borrowers they lend to. In particular, a lender who has provided credit to a borrower in the past knows more about that borrower than do all the other lenders. Label the informed or relationship lender an insider and the other lenders outsiders. I abstract from the process through which insiders acquire information, summarizing it instead by a positive probability of type discovery. Outsiders are not privy to the information gathered by insiders. To avoid situations where insiders design credit contracts to distort the beliefs of outsiders, assume that outsiders are also not privy to an insider's offer when they make their own offers. They do, however, find out if

\footnotetext{
${ }^{5} p(0) \theta_{1}>q \theta_{2}$ requires more algebra but yields similar conclusions.

${ }^{6}$ Essentially, lenders who need more capital can obtain it at the interbank rate while lenders who have enough capital interpret the rate as an opportunity cost.
} 
a borrower defaulted on a past loan and can revise their beliefs about the borrower's type conditional on this information. ${ }^{7}$

Firms borrow from one lender at a time while lenders can take on more than one borrower. Agents cannot commit to long-term contracts, inducing a sequence of one-period credit arrangements. This limits the scope for intertemporal incentives à la Townsend (1982) and keeps the focus on the learning property of relationship lending. ${ }^{8}$ Contracts are characterized by a loan rate so there is no quantity rationing in the model.

There are two notions of time: dates $t=1,2, \ldots$ denote calendar time in the general economy while periods $k=1,2, \ldots$ denote time spent by a borrower in the credit market. As will be described at the end of this section, borrowers can be exogenously separated from the credit market so the two notions of time are distinct.

At any date $t$, first-time (i.e., $k=1$ ) borrowers enter the market with private information about their types. All lenders have the same priors about a new borrower so this borrower chooses randomly among perfectly competitive lenders. Based on his type and the loan rate charged, the borrower then chooses which project to undertake. At the end of date $t$, project outcomes are realized and debts are settled. Capital is not destroyed in the production process so the borrowed unit is always recovered by the lender. Interest payments, however, can only be made by borrowers with successful projects. Lenders cannot observe the exact output of a project but can detect whether their borrowers have positive consumption so borrowers settle interest payments if and only if their projects are successful. Default occurs when a borrower cannot pay interest. Since this happens when his project yields no output, the probability of default is just the probability of project failure.

Also at the end of date $t$, a lender learns the type of his first-time borrower with proba-

\footnotetext{
${ }^{7}$ This is the only cost of default in the model. If the borrower is also forced to wait a few periods before his next contract, the marginal type that chooses the risky project may fall but the qualitative conclusions of the model are unlikely to change.

${ }^{8}$ Note that the scope is limited but not necessarily eliminated. In the environment presented in the supplementary appendix, for example, first period defaulters end up with higher loan rates the next time around so there is effectively an intertemporal punishment for choosing the riskier project. However, the punishment is not complete since uncommitted borrowers can switch to another lender and this new lender may not find it optimal to punish default as much as the original lender would have liked.
} 
bility $\phi \in(0,1]$. To simplify the exposition, I consider $\phi=1$ here. All other lenders learn whether or not the borrower defaulted on his first period loan. The borrower then moves to date $t+1$ and becomes a second-time (i.e., $k=2$ ) borrower. Conditional on their cost of funds and their beliefs about the borrower's type, lenders set their second period loan rates simultaneously. ${ }^{9}$ Since insiders and outsiders have different information sets, the borrower no longer chooses among perfectly competitive lenders. After receiving all offers, the borrower decides which contract to accept and which project to then undertake. Once again, project outcomes are realized and debts are settled.

At the end of date $t+1$, the types of all second-time borrowers are made public. This is done to avoid carrying credit history throughout the model and, therefore, to keep the state space finite. Also starting at the end of the borrower's second period is a positive probability $\mu \in(0,1)$ of exogenous separation from the credit market. This separation eliminates all information about the borrower and requires that he draw a new type and re-enter the market as a first-time borrower in $t+2$. In contrast, borrowers that are not separated become thirdtime borrowers in $t+2$. As before, loan rates are determined, lenders and projects chosen, outcomes realized, and debts settled. Borrowers who do not survive separation at the end of their third period must start anew while borrowers who do survive it become fourth-time borrowers in $t+3$ and face the same environment they did in $t+2$. The market continues in this way and, even though information is revealed after two periods, the possibility of exogenous separation ensures that there are always first-time, second-time, and advanced (i.e., $k \geq 3$ ) borrowers at any date $t$.

The three borrower classes can be interpreted as an approximation of the borrower life cycle. When a borrower first enters the credit market, little is known about him so $k=1$ reflects the market for new borrowers. In contrast, after sufficiently many realizations of the borrower's credit history, all lenders can form precise beliefs about his type so $k \geq 3$ approximates the market for established borrowers. $k=2$ captures the intermediate market:

\footnotetext{
${ }^{9}$ As we will see in Section 3, the type-independent nature of P2 allows for a pure strategy equilibrium in the simultaneous game between second period lenders.
} 
after enough time has elapsed for lending relationships to inform insiders but before enough time has elapsed for credit history to inform outsiders.

\section{Optimal Decisions}

I now characterize the optimal decisions for each period of the credit market. In what follows, the value of a lender with cost $r$ and information set $\Omega$ about a period $k$ borrower is denoted by $J_{k}(r \mid \Omega)$. His optimal loan rate offer is then denoted by $R_{k}^{*}(r \mid \Omega)$. It will be convenient to study the optimization problems recursively, starting with the market for advanced borrowers.

\subsection{Advanced Borrowers $(k \geq 3)$}

Since the types of advanced borrowers are public, the problem is one of perfect information

for $k \geq 3$. Project choice does not affect future outcomes as borrowers either start anew with exogenous probability $\mu$ or continue to period $k+1$ with exogenous probability $1-\mu$. Consequently, each borrower will choose the project that yields him a higher expected return in the current period. A trade-off arises, however, since $P 1$ generates more expected revenue but also increases the likelihood of interest payments. At high loan rates then, the borrower may have an incentive to choose the riskier project. Formally, the borrower's optimal strategy is characterized relative to a threshold loan rate. For a type $\omega$ borrower, the one-period return to $P 1$ is $p(\omega)\left[\theta_{1}-R\right]$ and the one-period return to $P \mathscr{2}$ is $q\left[\theta_{2}-R\right]$. The loan rate that makes him indifferent between the two projects is:

$$
\bar{R}(\omega)=\frac{p(\omega) \theta_{1}-q \theta_{2}}{p(\omega)-q}
$$

where $\bar{R}(0)=0$ and $\bar{R}^{\prime}(\omega)>0$. Type $\omega$ borrowers thus choose $P 1$ if charged $R \leq \bar{R}(\omega)$ and $P^{2}$ otherwise. I summarize this strategy as follows: 


$$
\bar{\gamma}(R \mid \omega)=\left\{\begin{array}{cll}
p(\omega) & \text { if } & R \leq \bar{R}(\omega) \\
q & \text { if } & R>\bar{R}(\omega)
\end{array}\right.
$$

Given the borrower's project strategy, lenders choose the loan rate. ${ }^{10}$ With probability $\mu$, lenders in $k \geq 3$ are separated from their borrowers and must start the next period with a first-timer. All lenders have the same information set in $k=1$ so competition forces expected profits there to zero. Symmetric information in periods $k \geq 3$ also means zero profits. Therefore, the expected revenue of an informed lender who charges his type $\omega$ borrower $R$ is $\bar{\gamma}(R \mid \omega) R$. Proposition 1 establishes the optimal loan rate offer:

Proposition 1 Define the following critical type:

$$
\widetilde{\omega}(r) \equiv \arg \min _{\omega \in[0,1]}|p(\omega) \bar{R}(\omega)-r|
$$

In the competition for $k \geq 3$ borrowers, lenders offer:

$$
R_{k \geq 3}^{*}(r \mid \omega)= \begin{cases}r / q & \text { if } \omega \in[0, \widetilde{\omega}(r)) \\ r / p(\omega) & \text { if } \omega \in[\widetilde{\omega}(r), 1]\end{cases}
$$

Since $p(\cdot) \bar{R}(\cdot)$ is monotonically increasing, $\widetilde{\omega}(r)$ is unique and increasing in $r$. Moreover, $p^{\prime}(\cdot)>0$ and $p(\cdot)>q$ imply that lower types are charged higher loan rates at any given policy rate, consistent with their more costly nature.

\subsection{Intermediate Borrowers $(k=2)$}

In the second period, first period credit histories are made public. Denote default by $d=D$ and non-default by $d=N$. While this is the only information observed by outside lenders, an insider also learns his borrower's type before making an offer. This type is revealed to

\footnotetext{
${ }^{10}$ Since an advanced borrower operates in an environment of perfect information and homogeneous separation rates, he attracts the same offer from every lender and is thus indifferent among them. Without loss of generality, I complete the borrower's strategy by assuming that he stays with his second period lender for all $k \geq 3$.
} 
outsiders at the end of $k=2$ though so the borrower's future outcomes are independent of current project choice and the optimal strategy of a type $\omega$ borrower is still given by $\bar{\gamma}(R \mid \omega)$.

As discussed in Section 2, the game between second period lenders is simultaneous. Consider first an insider who has discovered that his borrower is type $\omega$. With competition driving future profits to zero, the insider's expected revenue is again $\bar{\gamma}(R \mid \omega) R$. Now, however, the insider has an informational advantage over all other lenders so competition will not necessarily eliminate current profits. Noting that the insider can charge above the outsider rate and lose the borrower, his value is:

$$
J_{2}(r \mid \omega, d)=\max \left\{0, \max _{R} \bar{\gamma}(R \mid \omega) R-r \text { s.t. } R \leq R_{2}^{*}(r \mid d)\right\}
$$

Below $\bar{R}(\omega)$, the insider's revenue is strictly increasing in $R$. Therefore, if $R_{2}^{*}(r \mid d) \leq \bar{R}(\omega)$, equation (5) reduces to $J_{2}(r \mid \omega, d)=\max \left\{0, p(\omega) R_{2}^{*}(r \mid d)-r\right\}$. Now suppose $R_{2}^{*}(r \mid d)>$ $\bar{R}(\omega)$. The insider will either offer $R=\bar{R}(\omega)$ and induce the selection of $P 1$, offer $R=$ $R_{2}^{*}(r \mid d)$ and induce the selection of $P \mathscr{2}$, or offer $R>R_{2}^{*}(r \mid d)$ and lose the borrower. Without loss of generality, I assume that insiders only keep borrowers who net them positive expected profit. ${ }^{11}$ Proposition 2 establishes that the second period credit market splits neatly between insiders and outsiders. In particular, lending relationships are formed with better borrowers, consistent with the empirical prediction of Memmel et al (2007) that high quality firms are more likely to choose relationship lenders.

Proposition 2 For a given credit history d, outsiders attract second-period borrowers with $\omega \in\left[0, c_{d}(r)\right]$ and insiders retain those with $\omega \in\left(c_{d}(r), 1\right]$, where $c_{d}(r)$ is a threshold borrower type that satisfies $J_{2}\left(r \mid c_{d}(r), d\right)=0$.

Consider now an outsider who has attracted a $k=2$ borrower. Represent his beliefs about the borrower's type by a cumulative distribution function, $\widehat{F}_{d}(\cdot)$, defined over the

\footnotetext{
${ }^{11}$ This assumption simplifies the exposition aimed at here but is innocuous. Assuming instead that the insider keeps types for which he is indifferent yields the same loan rates and output functions derived below but the split between borrowers may occur within the insider rather than across insiders and outsiders.
} 
interval $\left[0, c_{d}(r)\right]$ according to Bayes' rule. Whatever the borrower's type, it will be known to everyone next period so future profits will be competed away. The expected profit of an outsider who charges his group $d$ borrower $R_{d}$ is thus:

$$
\int_{0}^{c_{d}(r)} \bar{\gamma}\left(R_{d} \mid x\right) R_{d} d \widehat{F}_{d}(x)-r
$$

In equilibrium, the outsider's beliefs will depend on $R_{d}$. Moreover, all outsiders must have the same beliefs so competition also drives (6) down to zero. Proposition 3 summarizes the outcome of the game between inside and outside lenders vying for second-period borrowers:

Proposition 3 In the competition for $k=2$ borrowers, outsiders offer $R_{2}^{*}(r \mid d)=r / q$ and get $\omega \in[0, \widetilde{\omega}(r)]$. In contrast, insiders keep $\omega \in(\widetilde{\omega}(r), 1]$ by offering:

$$
R_{2}^{*}(r \mid \omega, d)= \begin{cases}\bar{R}(\omega) & \text { if } \quad \omega \in(\widetilde{\omega}(r), \widehat{\omega}(r)) \\ r / q & \text { if } \quad \omega \in[\widehat{\omega}(r), 1]\end{cases}
$$

where $\widetilde{\omega}(r)$ is as defined in Proposition 1 and $\widehat{\omega}(r) \equiv \arg \min _{\omega \in[0,1]}|q \bar{R}(\omega)-r|$.

Proposition 3 establishes two important results. First, when the insider discovers his borrower's type with certainty (i.e., $\phi=1$ ), default history is irrelevant. Second, instead of the monotonically increasing function of $r$ that would arise in a pooled equilibrium, relationship lenders charge their borrowers a flat rate over certain ranges of the policy rate.

The adverse selection problem faced by competitive outsiders is key for the first result. Insiders want to keep the best types and, since outsiders cannot observe insider offers before making their own, no inferences about type can be made based on loan rates. For each default group then, outsiders know that they will attract the bottom of the distribution so they offer $r / q$, the maximum competitive rate. This rate is above $\bar{R}(\omega)$ for $\omega<\widehat{\omega}(r)$ so, instead of matching the outsider and inducing $P$ 2, the insider can offer these borrowers $\bar{R}(\omega)$ and induce $P 1$. Given $(3), \widetilde{\omega}(r)$ is the lowest type for which undercutting the outsider is profitable and the market splits according to it. ${ }^{12}$

\footnotetext{
${ }^{12}$ Note, however, that $d$ would not be irrelevant if $\phi<1$. Instead, $\phi<1$ implies a positive probability that no one is informed about the borrower's type in $k=2$, making credit history the only piece of information available to the market and mitigating the adverse selection problem.
} 
The second result from Proposition 3 is illustrated in Figure 1(a). Details on the construction of the figure are provided in the Appendix. Consider type $\omega_{A}$ as shown on the vertical axis. If $r>r_{B}$, then $\omega_{A}$ falls below $\widetilde{\omega}(r)$ and the borrower moves to an outsider. If $r \leq r_{B}$, then $\omega_{A}$ stays with his insider and, for policy rates between $r_{A}$ and $r_{B}$, he is charged his reservation loan rate. For policy rates below $r_{A}$, the insider charges him $r / q$ but $\omega_{A}$ is sufficiently high that this rate is less than $\bar{R}\left(\omega_{A}\right)$. Notice the role of relationship lending here: by revealing type to the insider, it allows him to gauge how much can be extracted from the borrower without inducing the risky project. In equilibrium, policy rates between $r_{A}$ and $r_{B}$ are such that the insider profits from using information generated by his lending relationship with $\omega_{A}$ to undercut the outsiders. The shaded region in Figure 1(a) illustrates that the length of the interval over which a borrower is charged his reservation rate is increasing in the borrower's type. Figure 1(a) also demonstrates that the proportion of types charged their reservation rate as a result of relationship lending exhibits a humpshaped response to increases in the policy rate (i.e., the vertical distance between $\widetilde{\omega}(r)$ and $\widehat{\omega}(r)$ rises then falls). As $r$ increases, the marginal type on which an insider breaks even rises so the fraction of borrowers admitted into lending relationships falls. Within the group of relationship borrowers, however, the insider wants to increase the marginal type that he undercuts on. Initially, the second effect dominates the first and the vertical distance rises but, eventually, the first effect dominates the second and the vertical distance falls.

Before proceeding to $k=1$, let us elaborate on the role of outsiders in these results. The free entry of other lenders forces the insider to solve a constrained optimization problem and, with monopoly rents precluded, insiders choose to tailor contracts around reservation rates in the manner discussed above. ${ }^{13}$ The absence of monopoly rents, however, does not mean the absence of all rents: (3) and $q<p(\omega)$ imply $R_{2}^{*}(r \mid \omega, d)>r / p(\omega)$, where $r / p(\omega)$

\footnotetext{
${ }^{13}$ In other words, competition prevents the borrower from being informationally captured and, as in Schmeits (2005), mitigates the hold-up problem. The result that competition can help sustain a mutually beneficial second-period credit contract contrasts somewhat with the Petersen and Rajan (1995) argument that concentration increases the value of lending relationships. Therefore, consistent with Cao and Shi (2001), the treatment of information appears critical in analyzing interactions between credit market structure and credit market outcomes.
} 
is the zero-profit loan rate derived in Subsection 3.1 for $\omega>\widetilde{\omega}(r)$. Moreover, the fact that the insider simply matches the outsider rate for types above $\widehat{\omega}(r)$ is consistent with the empirical finding of Bharath et al (2009) that prices of relationship and non-relationship loans are indistinguishable for borrowers at the top of the asset size distribution. ${ }^{14}$ Here though, $\widehat{\omega}^{\prime}(r)>0$ so the fraction of borrowers for which insider and outsider prices are indistinguishable declines with the policy rate.

\subsection{New Borrowers $(k=1)$}

Recall from Proposition 3 that the second period equilibrium does not depend on default history when $\phi=1$. Therefore, the reservation rate of a first-time borrower is still $\bar{R}(\omega)$ and his project strategy is once again $\bar{\gamma}(R \mid \omega)$ as defined in (2). Moreover, the $d$ 's drop out of (5) and the insider's valuation of a second period contract with a type $\omega$ borrower can be denoted by $J_{2}(r \mid \omega)$. Assuming for now that the future policy rate is expected to be the same as the current one, first period lenders obtain the following expected profit from charging their borrowers $R_{1}$ :

$$
\int_{0}^{1} \bar{\gamma}\left(R_{1} \mid x\right) R_{1} d F(x)+\beta \int_{\widetilde{\omega}(r)}^{1} J_{2}(r \mid x) d F(x)-r
$$

Let $R_{1}(r)$ denote the equilibrium first period loan rate and define type $\xi(r)$ such that $\bar{R}(\xi(r))=R_{1}(r) .{ }^{15}$ By this definition, all types above $\xi(r)$ choose $P 1$ and all types below it choose P2. Since competition between identically uninformed lenders drives (8) down to zero, $\xi(r)$ is characterized by:

$$
\xi(r) \equiv \arg \min _{\omega \in[0,1]}\left|\left[\int_{0}^{\omega} q d F(x)+\int_{\omega}^{1} p(x) d F(x)\right] \bar{R}(\omega)+\beta \int_{\widetilde{\omega}(r)}^{1} J_{2}(r \mid x) d F(x)-r\right|
$$

where (5) and Proposition 3 can be used to substitute out $J_{2}(r \mid x)$. Further discussion of $\xi(r)$ is deferred until Section 4. For now though, note that a continuous function over a

\footnotetext{
${ }^{14}$ To the extent that ability and assets are positively correlated, the distribution of assets can be viewed as one approximation of the distribution of types.

${ }^{15}$ If $R_{1}(r)>\bar{R}(1)$, then $\xi(r)$ is corner at 1 .
} 
compact set has at least one argmin and, as demonstrated in the Appendix, the argmin that defines $\xi(r)$ is unique and non-decreasing under the following regulatory conditions:

Assumption $1 f(\cdot)$ is well-behaved with $f(1) \leq 1$

Assumption $2 p(0) \geq q+\frac{[p(1)-q]^{3}}{q p^{\prime}(1)+[p(1)-q]^{2}}$

Assumption $3 p^{\prime \prime}(\cdot)$ is sufficiently low

Assumption $4 p(1) \leq 2 q$

Assumption 1 precludes the economy from having a disproportionately large group of high types. It is a relatively innocuous assumption, satisfied by both uniform and truncated normal distributions over the unit interval. In Section 2, we imposed $p(0)>q$ so Assumption 2 just restricts the margin by which $p(0)$ exceeds $q$. Assumption 3 says that $p(\cdot)$ is either concave, linear, or mildly convex. In other words, while the probability of succeeding in the investment project increases with firm type, it does not increase exponentially. Finally, Assumption 4 regulates the outside option by putting a lower bound on $q$.

\section{Output Functions}

From the preceding analysis, there are two channels through which relationship lending can affect economic activity. First and as demonstrated in Subsection 3.2, insiders use the information they acquire over the course of their relationships to tailor loan rates nonmonotonically. Second and as visible in Subsection 3.3, the loan rate for new borrowers depends on expectations of future relationship profits. Having determined the effect of relationship lending on credit terms, let us now formalize its effect on the output produced under these terms. As will become apparent below, the key variables for the output calculation are the cutoff types $\widetilde{\omega}(r)$ and $\xi(r)$. 


\subsection{Advanced Borrowers $(k \geq 3)$}

Proposition 1 established that $R_{k \geq 3}^{*}(r \mid \omega)=r / p(\omega)$ for all $\omega \geq \widetilde{\omega}(r)$ and, according to the borrower strategy in (2), this loan rate will induce investment in $P 1$ as long as $r / p(\omega) \leq$ $\bar{R}(\omega)$. Given (3), the latter condition is guaranteed by $\omega \geq \widetilde{\omega}(r)$ so we can conclude that all advanced borrowers above $\widetilde{\omega}(r)$ choose P1. Consider now $\omega<\widetilde{\omega}(r)$. Proposition 1 also established that $R_{k \geq 3}^{*}(r \mid \omega)=r / q$ for borrowers below $\widetilde{\omega}(r)$ so they will choose $P 2$ as long as $r / q>\bar{R}(\omega)$. A sufficient condition for this inequality is $r>p(\omega) \bar{R}(\omega)$, which is guaranteed by $\omega<\widetilde{\omega}(r)$. Normalized by population then, the total output of advanced borrowers is:

$$
Y_{k \geq 3}(r)=\int_{0}^{\widetilde{\omega}(r)} q \theta_{2} d F(x)+\int_{\widetilde{\omega}(r)}^{1} p(x) \theta_{1} d F(x)
$$

With $\widetilde{\omega}^{\prime}(r)>0$ and $p(x) \theta_{1}>q \theta_{2}$ for $x \in(0,1]$, equation (10) defines an output function that is decreasing in the policy rate.

\subsection{Intermediate Borrowers $(k=2)$}

Proposition 3 established that intermediate borrowers below $\widetilde{\omega}(r)$ are financed by outsiders at loan rate $r / q$. From the previous subsection, we know that $r / q$ induces types below $\widetilde{\omega}(r)$ to choose the speculative project so we can conclude that all intermediate borrowers below $\widetilde{\omega}(r)$ undertake P2. Proposition 3 also established that intermediate borrowers with $\omega \in(\widetilde{\omega}(r), \widehat{\omega}(r))$ are financed by insiders at loan rate $\bar{R}(\omega)$ so, given (2), they clearly choose $P 1$. Consider now intermediate borrowers above $\widehat{\omega}(r)$. These types are financed by insiders at loan rate $r / q$ so they will also choose $P 1$ as long as $r / q<\bar{R}(\omega)$. With $\widehat{\omega}(r)$ as defined in Proposition 3, the latter condition is guaranteed by $\omega \geq \widehat{\omega}(r)$ and we can conclude that all intermediate borrowers above $\widetilde{\omega}(r)$ choose $P 1$. In other words, $Y_{2}(r)$ is also given by (10).

\subsection{New Borrowers $(k=1)$}

As discussed in Subsection 3.3, the loan rate for first-time borrowers induces all types above $\xi(r)$ to choose $P 1$ and all types below it to choose P2. Therefore, the total output of new 
borrowers is:

$$
Y_{1}(r)=\int_{0}^{\xi(r)} q \theta_{2} d F(x)+\int_{\xi(r)}^{1} p(x) \theta_{1} d F(x)
$$

With $\xi^{\prime}(r)>0$, equation (11) also defines an output function that is decreasing in the policy rate.

\subsection{Aggregation}

There are new, intermediate, and advanced borrowers at any date $t$ so we must determine the distribution of borrowers across periods in order to calculate aggregate output. Without loss of generality, set the population size to one and let $\Psi_{1, t}, \Psi_{2, t}$, and $\Psi_{k \geq 3, t}$ denote the proportions of period 1,2 , and $k \geq 3$ borrowers at date $t$. Aggregate output can then be written as:

$$
Y(r, t)=\Psi_{1, t} Y_{1}(r)+\Psi_{2, t} Y_{2}(r)+\Psi_{k \geq 3, t} Y_{k \geq 3}(r)
$$

where $Y_{1}(r)$ and $Y_{2}(r)=Y_{k \geq 3}(r)$ are given by (11) and (10) respectively. With the possibility of exogenous separation beginning at the end of the second period, the distribution evolves according to:

$$
\begin{aligned}
& \Psi_{1, t+1}=\mu\left(\Psi_{2, t}+\Psi_{k \geq 3, t}\right) \\
& \Psi_{2, t+1}=\Psi_{1, t} \\
& \Psi_{k \geq 3, t+1}=1-\Psi_{1, t+1}-\Psi_{2, t+1}
\end{aligned}
$$

Substituting $\Psi_{k \geq 3, t}$ into the expression for $\Psi_{1, t+1}$, the evolution of $\Psi_{1}$ is determined by a one-dimensional difference equation and, with $\mu \in(0,1)$, the entire system is asymptotically stable. Therefore, starting from any initial distribution, the proportions converge to $\Psi_{1}=$ $\Psi_{2}=\frac{\mu}{1+\mu}$ and $\Psi_{k \geq 3}=\frac{1-\mu}{1+\mu}$. Steady state aggregate output is thus:

$$
Y(r)=\frac{\mu}{1+\mu} Y_{1}(r)+\frac{1}{1+\mu} Y_{k \geq 3}(r)
$$


Moreover, the extent of relationship lending is captured by $(1-\widetilde{\omega}(r)) /(1+\mu)$ and is decreasing in the policy rate and the rate of exogenous separation.

\subsection{Benchmark for Comparison}

To better appreciate the macroeconomic effects of relationship lending, it will be instructive to compare the results of my model to those of a standard credit channel model where exogenous separation occurs with certainty every period and private information is never revealed. In this context, a representative lender's expected profit from charging $R_{S}$ is $\int_{0}^{1} \bar{\gamma}\left(R_{S} \mid x\right) R_{S} d F(x)-r$. Competition drives this expression down to zero and yields an equilibrium loan rate denoted by $R_{S}(r)$. Defining type $\eta(r)$ such that $\bar{R}(\eta(r))=R_{S}(r)$, the solution to the standard model and the resulting output function are characterized by (13) and (14) respectively:

$$
\begin{aligned}
& \eta(r) \equiv \arg \min _{\omega \in[0,1]}\left|\left[\int_{0}^{\omega} q d F(x)+\int_{\omega}^{1} p(x) d F(x)\right] \bar{R}(\omega)-r\right| \\
& Y_{S}(r)=\int_{0}^{\eta(r)} q \theta_{2} d F(x)+\int_{\eta(r)}^{1} p(x) \theta_{1} d F(x)
\end{aligned}
$$

\section{Output Implications by Borrower Class}

Given the output functions derived above, the effect of relationship lending on per-period output can be gauged by comparing $\widetilde{\omega}(r), \xi(r)$, and $\eta(r)$. The key properties of these cutoffs are derived in the Appendix and illustrated in Figure 1(b). The implied output functions are then shown in Figure 2(a). ${ }^{16}$

\subsection{Output of Advanced and Intermediate Borrowers}

Begin with $\widetilde{\omega}(r)$ and $\eta(r)$. Aside from the corners, $\eta(r)$ only intersects $\widetilde{\omega}(r)$ once. Moreover, $\eta(r)$ approaches this intersection from below $\widetilde{\omega}(r)$. Given the output functions in (10) and

\footnotetext{
${ }^{16}$ Since all output functions were normalized by population, they are directly comparable.
} 
(14), we can then conclude that $Y_{S}(r)$ is greater than $Y_{k \geq 3}(r)$ for low policy rates but less than $Y_{k \geq 3}(r)$ otherwise. The difference between $Y_{k \geq 3}(r)$ and $Y_{S}(r)$ is intuitive. At low policy rates, informed lenders can grant favourable credit terms (i.e., loan rates low enough to induce $P 1)$ to more types without suffering a loss. The same is true for uninformed lenders in the standard model but, since they can only offer a pooled rate, some of the lower types who would not otherwise receive favourable terms now do. In contrast, when the cost of funds is sufficiently high, this mechanism has the opposite effect, yielding $\eta(r)>\widetilde{\omega}(r)$ and $Y_{S}(r)<Y_{k \geq 3}(r)$. As can be gleaned from Subsection 3.2, relationship lending results in credit terms which push $Y_{2}(r)$ towards $Y_{k \geq 3}(r)$ so the first macroeconomic impact of these relationships is a less severe second period output profile relative to the standard model.

\subsection{Output of New Borrowers}

Consider now $\xi(r)$ and $\eta(r)$. Aside from the corners, $\eta(r)$ does not intersect $\xi(r)$. Instead, $\xi(r)<\eta(r)$ which implies $Y_{1}(r)>Y_{S}(r)$. Therefore, even though the first period of the baseline model is characterized by the same information frictions as the standard one, it generates higher output. To see why, note that first period lenders compete more fiercely for borrowers in anticipation of the second period insider profits afforded by relationship lending. As a result, the pooled rate is driven down further, a greater number of types opt for $P 1$, and the second macroeconomic impact of relationship lending is an improvement in first period output relative to the standard model. This effect is most pronounced over moderate policy rates since very high values of $r$ are associated with few lending relationships while very low values of $r$ provide only limited scope for further reductions in the pooled rate.

\section{Implications for Aggregate Output}

How do these effects roll up into economy-wide output? In this section, I establish that relationship lending leads to a smoother steady state aggregate output function and a less dramatic response to certain monetary shocks. 


\subsection{Steady State}

Aggregate steady state results are illustrated in Figure 2(b). With a higher probability of exogenous separation, there is a greater mass of first-time borrowers and the benefits of relationship lending are more visible at moderate policy rates. In contrast, lower separation probabilities push $Y(r)$ towards $Y_{k \geq 3}(r)$ and magnify the benefits of relationship lending at higher policy rates. For any value of $\mu$ though, $Y(r)$ is better than $Y_{S}(r)$ in two respects. First, $Y(r)$ is smoother over the interval $r \in[0, q \bar{R}(1)]$ and, second, $Y(r)>q \theta_{2}=Y_{S}(r)$ over the interval $r \in[q \bar{R}(1), p(1) \bar{R}(1))$. Proposition 4 establishes the smoothness result more formally. To simplify the exposition both here and in the next subsection, I strengthen Assumptions 1 and 3 so that $f(\cdot)=1$ and $p^{\prime \prime}(\cdot)=0$.

Proposition 4 Let smoothness be a notion of curvature and define the smoothness of $y(r)$ over $r \in[a, b]$ by $S \equiv \int_{a}^{b}\left|y^{\prime \prime}(r)\right| d r$. It can be shown that $\int_{0}^{q \bar{R}(1)}\left|Y^{\prime \prime}(r)\right| d r<\int_{0}^{q \bar{R}(1)}\left|Y_{S}^{\prime \prime}(r)\right| d r$, implying that $Y(r)$ is smoother than $Y_{S}(r)$. The same conclusion holds if smoothness is taken to be a notion of dependence and defined by $\widehat{S} \equiv \int_{a}^{b}\left|y^{\prime}(r)\right| d r$.

In words, Proposition 4 says that relationship lending smooths the aggregate output function both by decreasing the average curvature of this function and by decreasing the average dependence of steady state output on policy rates.

To see that the smoothing effect does not result from the timing of exogenous separation or the fact that information is eventually revealed to all lenders, suppose that separation occurs with probability $\mu$ at the end of the first period and probability 1 at the end of the second. The $k=2$ problem is unchanged so $Y_{2}(r)$ is still given by (10). The $k=1$ problem is slightly different since the second term in (8) must now be multiplied by $(1-\mu)$. Once again though, higher values of $\mu$ imply that the economy is able to sustain fewer lending relationships so weight shifts from $Y_{2}(r)=Y_{k \geq 3}(r)$ to $Y_{1}(r)$ and the aggregate output function steepens. Moreover, with exogenous separation beginning at the end of period 1 , higher values of $\mu$ lead first period lenders to view future relationship profits as less 
likely, pushing $\xi(r)$ closer to $\eta(r), Y_{1}(r)$ closer to $Y_{S}(r)$, and actually hastening the fall in output. Therefore, the institutional parameters that affect an economy's ability to sustain lending relationships affect its real response to policy. Here, $\mu$ can be interpreted as the firm death rate and, as suggested by Adachi and Aidis (2007), its magnitude is influenced by the regulatory environment (i.e., enforcement of property rights, anti-trust laws, hiring and firing restrictions, predatory tax practices, inspection agencies, etc.). ${ }^{17}$

\subsection{Dynamics}

Let us now investigate whether relationship lending also fosters smoothness in a stochastic environment. In particular, if the policy rate follows an $A R(1)$ process, does the presence of relationship lending generate a less volatile output response to temporary shocks? As proven in the Appendix and summarized in the following proposition, the answer is unambiguously yes for small shocks in an already contractionary environment. ${ }^{18}$ That is, when liquidity is low, relationship lending does indeed dampen the transmission of monetary policy and, for that matter, the transmission of further liquidity shocks.

Proposition 5 Suppose the policy rate evolves according to $r_{t}=r_{s s}+\alpha\left(r_{s s}-r_{t-1}\right)+\varepsilon_{t}$, where $r_{s s}$ is its steady state value, $\alpha$ captures the speed of mean reversion, and $\varepsilon_{t}$ is an IID shock. If $r_{s s}$ is high, then a small temporary shock - that is, a one-time shock that keeps the policy rate between 0 and $q \bar{R}(1)$ - induces a less volatile transition path when relationship lending is present.

Consider now a permanent shock. As long as the policy rate is expected to stay at its post-shock level, the total output of each borrower class - new, intermediate, and advanced - adjusts immediately to its new steady state. Recalling the laws of motion presented in

\footnotetext{
${ }^{17}$ In a more general version of the model, both $\mu$ and $\phi$ would qualify as institutional parameters with $\phi$ representing average lender quality.

${ }^{18}$ The effects in an expansionary environment are not as clear. For example, if $r_{s s}$ is very low and the shock is small enough, then the output of new borrowers will exhibit less volatility while that of intermediate and advanced borrowers will exhibit more.
} 
Subsection 4.4, the policy rate does not affect the distribution of borrowers across these classes so aggregate output also adjusts immediately after a permanent shock. In light of Proposition 4, the size of the adjustment will often be smaller in the presence of relationship lending so there is still a sense in which the transition is less pronounced.

This, however, raises the question of how distributional dynamics would affect the aggregate output response when credit markets feature relationship lending. To gain some insight into this issue, I consider the transmission of a permanent shock when the current model is extended to allow for different separation rates. In particular, I assume that borrowers who stay with their insiders have a lower probability of exogenous separation. The results so far suggest that this assumption is not unreasonable. As demonstrated above, relationship lending makes loans more accessible to new borrowers and sometimes induces lenders with intermediate borrowers not to increase loan rates. Since better credit terms may help borrowers overcome idiosyncratic events that would have otherwise put them out of business, relationship lending may indeed foster lower firm exit rates.

The difference in separation rates has two important implications. First and as noted above, it allows us to consider distributional dynamics. We have already seen that the policy rate affects which borrowers enter into lending relationships so, when separation rates differ between insiders and outsiders, the policy rate will also affect the distribution of borrowers across periods. Second, having different separation rates gives insiders more bargaining power over high types. A separated borrower must draw a new type and re-enter the credit market as a first-timer so separation is very costly for high- $\omega$ firms. By supporting a lower exit rate, insiders can now charge slightly above the outsider offer without losing these borrowers. The details of the extended model are provided in a supplementary appendix. Although the introduction of more bargaining power complicates the analysis, numerical results suggest that relationship lending induces distributional dynamics which then foster a more gradual output response to certain permanent shocks. 


\section{Conclusion}

This paper has constructed a credit-based model of production to examine how relationship lending affects the monetary transmission mechanism. I analyzed how monetary policy changes the incentives of borrowers and lenders to engage in lending relationships and how these changes then shape the response of aggregate output. I find that sufficiently good borrowers enter into lending relationships and, over intermediate ranges of the policy rate, their loan rates are policy-invariant and preferable to the terms offered by uninformed lenders. In addition, competition among lenders for future relationship profits alleviates some of the tightness that could otherwise arise in the market for new borrowers. On average then, the informational properties of relationship lending lead to improved credit terms and economies that can sustain these relationships have a smoother steady state aggregate output profile and a less dramatic response to certain monetary shocks. These results provide a theoretical basis for cross-country transmission differences via a relationship lending channel so future work will be directed at calibrations to quantify the effect. 


\section{References}

Adachi, Y., Aidis, R., 2007. Russia: Firm Entry and Survival Barriers. Economic Systems 31, 391-411.

Berger, A., Udell, G., 1995. Relationship Lending and Lines of Credit in Small Firm Finance. Journal of Business 68, 351-381.

Bernanke, B., 1983. Nonmonetary Effects of the Financial Crisis in the Propagation of the Great Depression. American Economic Review 73, 257-276.

Bernanke, B., Gertler, M., 1989. Agency Costs, Net Worth and Business Fluctuations. American Economic Review 79, 14-31.

Bharath, S., Dahiya, S., Saunders, A., Srinivasan, A., 2009. Lending Relationships and Loan Contract Terms. Forthcoming in Review of Financial Studies, doi:10.1093/rfs/hhp064.

Boot, A., 2000. Relationship Banking: What Do We Know? Journal of Financial Intermediation $9,7-25$.

Borio, C., Fritz, W., 1995. The Response of Short-Term Bank Lending Rates to Policy Rates: A Cross-Country Perspective. BIS Working Paper 27.

Bose, N., Cothren, R., 1997. Asymmetric Information and Loan Contracts in a Neoclassical Growth Model. Journal of Money, Credit, and Banking 29, 423-439.

Cao, M., Shi, S., 2001. Screening, Bidding, and the Loan Market Tightness. European Finance Review 5, 21-61.

Diamond, D., Dybvig, P., 1983. Bank Runs, Deposit Insurance, and Liquidity. Journal of Political Economy 91, 401-419.

Ehrmann, M., Gambacorta, L., Martínez-Pagés, J., Sevestre, P., Worms, A., 2001. Financial Systems and the Role of Banks in Monetary Policy Transmission in the Euro Area. Deutsche Bundesbank Discussion Paper 18/01.

Gambacorta, L., 2004. How Do Banks Set Interest Rates? NBER Working Paper 10295.

Gertler, M., 1988. Financial Structure and Aggregate Economic Activity: An Overview. Journal of Money, Credit, and Banking 20, 559-587.

Gertler, M., 1992. Financial Capacity and Output Fluctuations in an Economy with MultiPeriod Financial Relationships. Review of Economic Studies 59, 455-472.

Iacoviello, M., Minetti, R., 2008. The Credit Channel of Monetary Policy: Evidence from the Housing Market. Journal of Macroeconomics 30, 69-96.

Khan, A., Ravikumar, B., 2001. Growth and Risk-Sharing with Private Information. Journal of Monetary Economics 47, 499-521. 
King, R., Levine, R., 1993. Finance and Growth: Schumpeter Might Be Right. Quarterly Journal of Economics 108, 717-737.

Kiyotaki, N., Moore, J., 1997. Credit Cycles. Journal of Political Economy 105, 211-248.

Memmel, C., Schmieder, C., Stein, I., 2007. Relationship Lending - Empirical Evidence for Germany. Deutsche Bundesbank Discussion Paper 14/07.

Mojon, B., Peersman, G., 2003. A VAR Description of the Effects of Monetary Policy in the Individual Countries of the Euro Area. In: Angeloni, I., Kashyap, A., Mojon, B. (Eds.), Monetary Policy Transmission in the Euro Area. Cambridge University Press, New York, pp. 56-74.

Petersen, M., Rajan, R., 1995. The Effect of Credit Market Competition on Lending Relationships. Quarterly Journal of Economics 110, 407-443.

Schmeits, A., 2005. Discretionary Contracts, Competition and Bank-Firm Relationships. Washington University in St. Louis Working Paper.

Smith, A., Wang, C., 2006. Dynamic Credit Relationships in General Equilibrium. Journal of Monetary Economics 53, 847-877.

Townsend, R., 1982. Optimal Multiperiod Contracts and the Gain from Enduring Relationships under Private Information. Journal of Political Economy 90, 1166-1186.

Van Tassel, E., 2002. Signal Jamming in New Credit Markets. Journal of Money, Credit, and Banking 34, 469-490.

Weth, M., 2002. The Pass-Through from Market Interest Rates to Bank Lending Rates in Germany. Deutsche Bundesbank Discussion Paper 11/02.

Williamson, S., 1987. Financial Intermediation, Business Failures, and Real Business Cycles. Journal of Political Economy 95, 1196-1216. 
Figure 1: Critical Types

(a) Graphical representation of Proposition 3

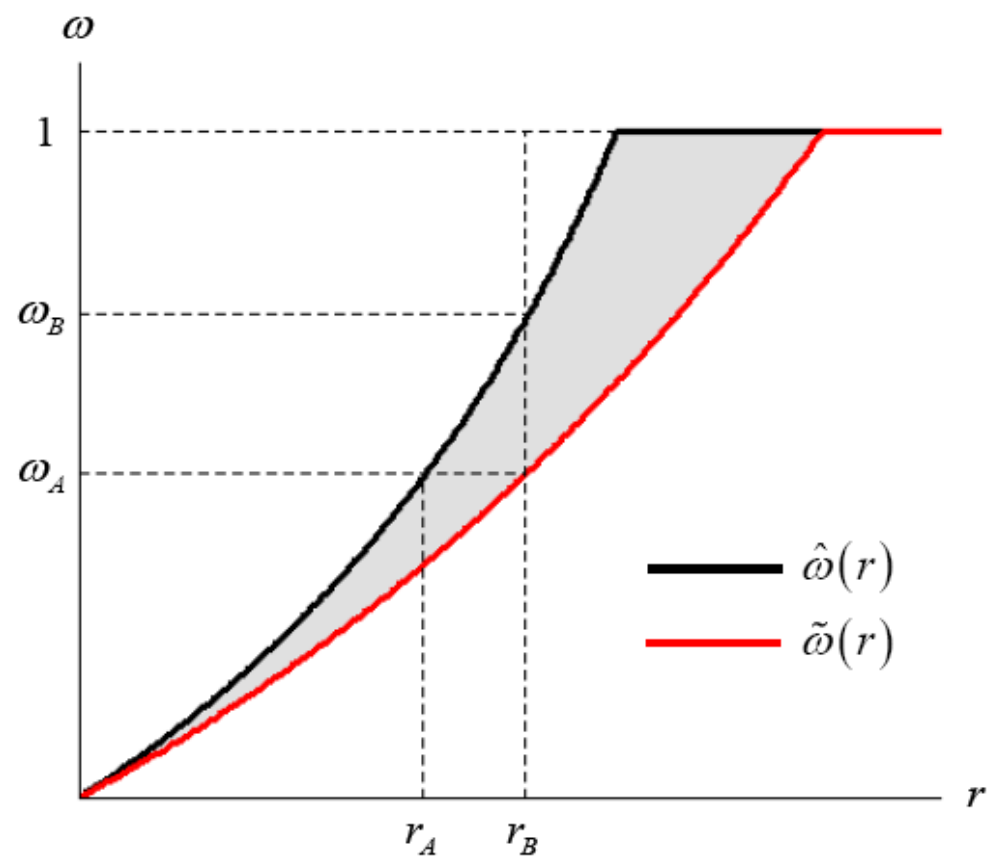

(b) Comparison of critical types

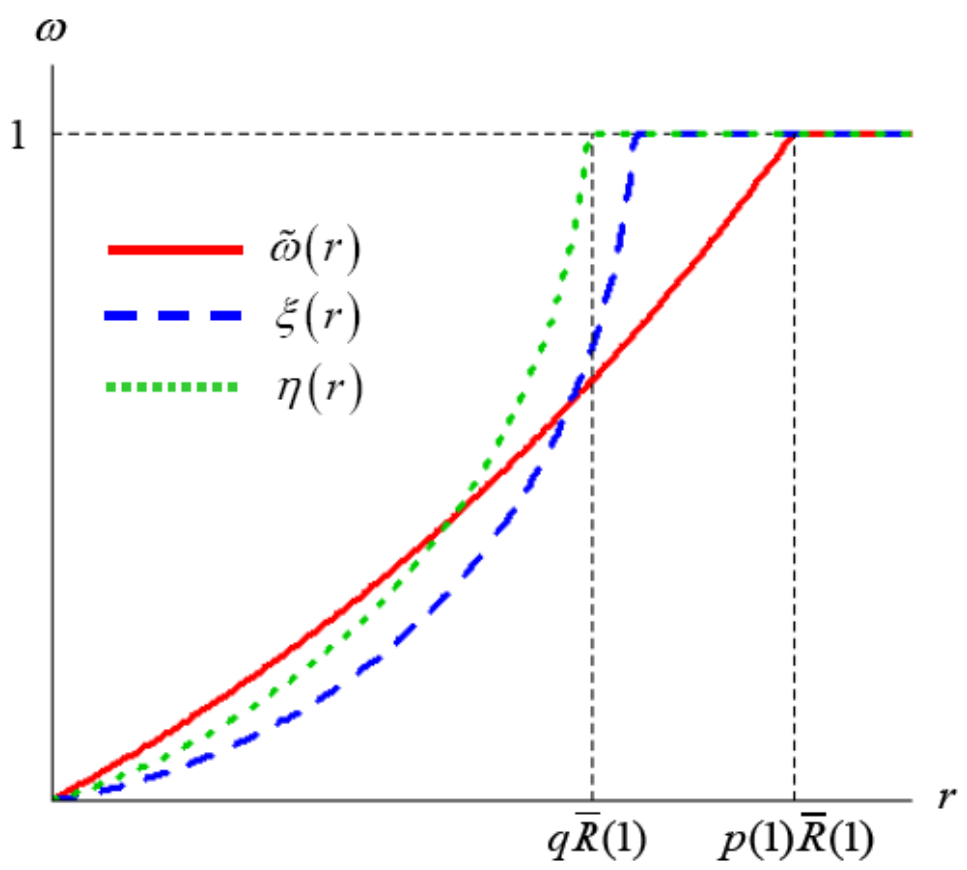


Figure 2: Steady State Output

(a) Per-period output functions

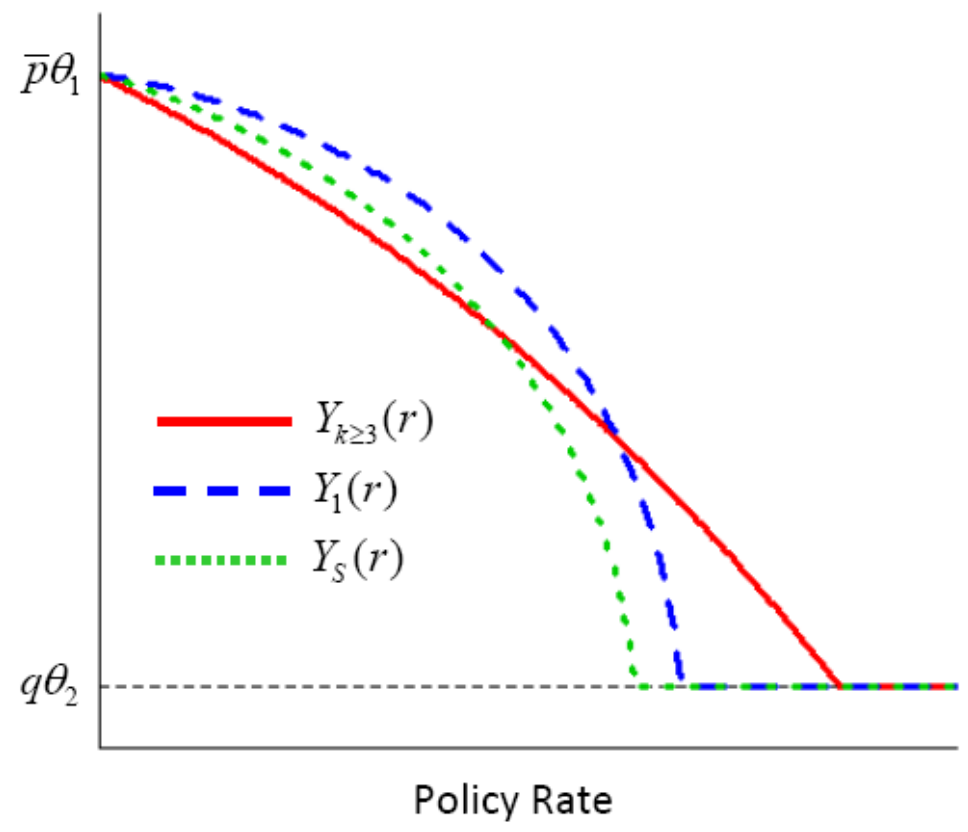

(b) Aggregate output functions

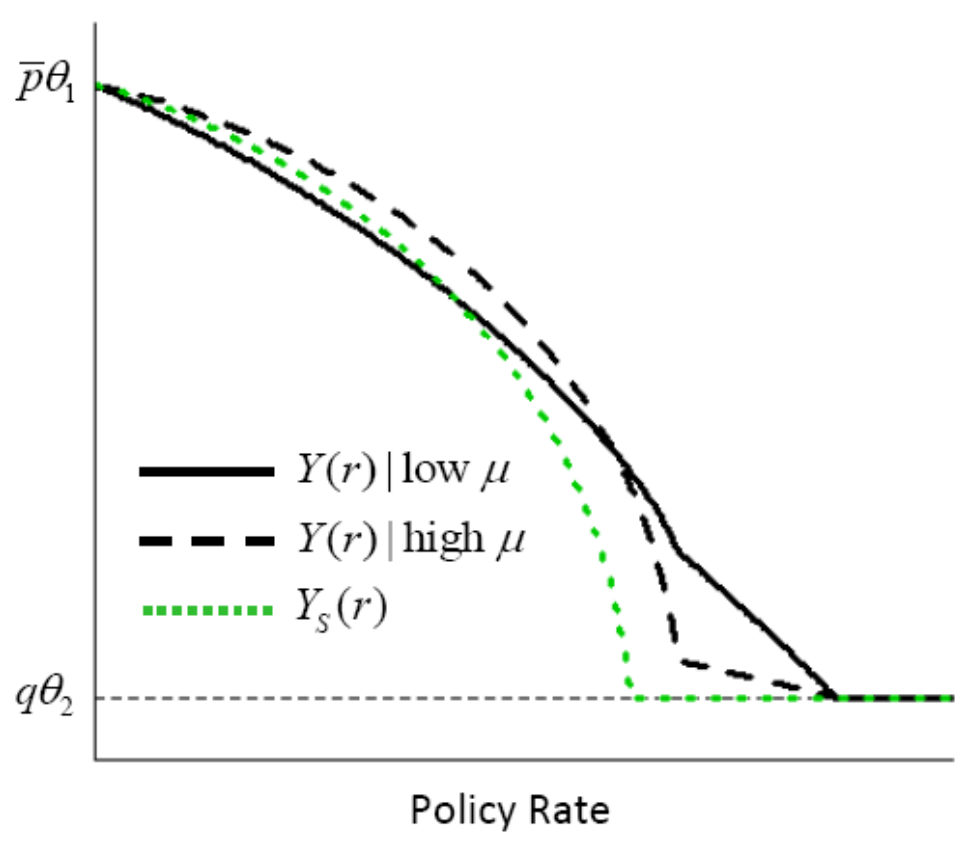




\section{Appendix: Proofs and Derivations}

This appendix proves Propositions 1 to 5 and derives the key features of Figure 1 . The material is presented in the order it is referenced in the main text.

\section{A. Proof of Proposition 1}

The highest sustainable loan rate is $\theta_{2}$ : anything above $\theta_{2}$ and the borrower will not want to undertake either project. For loan rates less than or equal to $\theta_{2}$, the lender's revenue function is:

$$
\bar{\gamma}(R \mid \omega) R=\left\{\begin{array}{lll}
p(\omega) R & \text { if } & R \leq \bar{R}(\omega) \\
q R & \text { if } & R>\bar{R}(\omega)
\end{array}\right.
$$

In equilibrium, competition forces $\bar{\gamma}(R \mid \omega) R=r$ so the zero-profit loan rates are:

$$
R= \begin{cases}r / p(\omega) & \text { if } \quad r \leq p(\omega) \bar{R}(\omega) \\ r / q & \text { if } \quad r>q \bar{R}(\omega)\end{cases}
$$

In other words, the lender charges $r / p(\omega)$ if $r \in[0, q \bar{R}(\omega)]$, either $r / p(\omega)$ or $r / q$ if $r \in(q \bar{R}(\omega), p(\omega) \bar{R}(\omega)]$, and $r / q$ if $r \in\left(p(\omega) \bar{R}(\omega), \theta_{2}\right]$. I now show that there exists a profitable deviation from $r / q$ when $r \in(q \bar{R}(\omega), p(\omega) \bar{R}(\omega)]$, ruling it out as an equilibrium offer. In particular, suppose the lender offers $\bar{R}(\omega)$ instead of $r / q$. Since $r>q \bar{R}(\omega)$, the lender can indeed do this without losing the borrower. Moreover, at $\bar{R}(\omega)$, type $\omega$ chooses $P 1$ so the lender's expected profit is $p(\omega) \bar{R}(\omega)-r>0$, confirming the profitable deviation. Therefore, the equilibrium loan rate for $k \geq 3$ is:

$$
R_{k \geq 3}^{*}(r \mid \omega)=\left\{\begin{array}{lll}
r / p(\omega) & \text { if } & r \leq p(\omega) \bar{R}(\omega) \\
r / q & \text { if } & r>p(\omega) \bar{R}(\omega)
\end{array}\right.
$$

The monotonicity of $p(\cdot) \bar{R}(\cdot)$ and the definition of $\widetilde{\omega}(r)$ then yield the form in $(4)$. 


\section{B. Proof of Proposition 2}

Suppose types $\omega_{0}$ and $\omega_{0}+\delta$ have the same credit history $d$. Since credit history is the only information that the outsider can condition on, he offers $\omega_{0}$ and $\omega_{0}+\delta$ the same loan rate $R_{2}^{*}(r \mid d)$. Consider now an insider who finds it optimal to keep $\omega_{0}$. Retaining $\omega_{0}$ when exogenous separation rates are homogeneous implies that the insider must be charging $R_{2}^{*}\left(r \mid \omega_{0}, d\right) \leq R_{2}^{*}(r \mid d)$. Moreover, the fact that the insider finds it optimal to keep $\omega_{0}$ means that he must be making positive profit on this borrower. With $\delta>0$ and $\bar{R}^{\prime}(\omega)>0$, equation (2) establishes that $\bar{\gamma}\left(R \mid \omega_{0}+\delta\right) \geq \bar{\gamma}\left(R \mid \omega_{0}\right)$ for any $R$. Therefore, the insider could offer $\omega_{0}+\delta$ loan rate $R_{2}^{*}\left(r \mid \omega_{0}, d\right)$, keep him, and make at least as much as he is making on $\omega_{0}$. Since $\omega_{0}$ and $\delta$ were chosen arbitrarily, Proposition 2 follows by induction.

\section{Proof of Proposition 3}

Let $R_{d}(r)$ denote the as yet undetermined solution to the outsider's problem and define type $\omega_{d}(r)$ such that $\bar{R}\left(\omega_{d}(r)\right)=R_{d}(r)$. By definition, all types above $\omega_{d}(r)$ choose $P 1$ and all types below it choose $P 2$ so setting (6) to zero yields:

$$
R_{d}(r)=\left\{\begin{array}{lll}
r /\left[\int_{0}^{\omega_{d}(r)} q d \widehat{F}_{d}(x)+\int_{\omega_{d}(r)}^{c_{d}(r)} p(x) d \widehat{F}_{d}(x)\right] & \text { if } & \omega_{d}(r) \leq c_{d}(r) \\
r / q & \text { if } & \omega_{d}(r)>c_{d}(r)
\end{array}\right.
$$

The proof of Proposition 3 proceeds in three steps. First, I prove $R_{2}^{*}(r \mid d)=r / q$. Second, I prove $c_{d}(r)=\widetilde{\omega}(r)$. Third, I establish equation (7). The following Lemma will be useful for the first step:

Lemma $1 \widehat{F}_{d}(\cdot)$ is the CDF of a non-degenerate distribution.

Proof. Using Bayes' Rule, $\widehat{F}_{d}(x)$ is given by:

$$
\widehat{F}_{d}(x) \equiv \operatorname{Pr}(\omega \leq x \mid d)=\frac{\operatorname{Pr}(d \mid \omega \leq x) \operatorname{Pr}(\omega \leq x)}{\operatorname{Pr}(d)}
$$


All first-time borrowers advance to the second period so the unconditional type distribution is $F(\cdot)$. Note, however, that $\operatorname{Pr}(\omega \leq x)=F(x) / F\left(c_{d}(r)\right)$ since the outsider only gets $\omega \in\left[0, c_{d}(r)\right]$. If $c_{d}(r) \leq \xi(r)$, where $\xi(r)$ is the lowest type that chose P1 in the first period, then the outsider's beliefs are given by:

$$
\widehat{F}_{d}(x)=\frac{F(x)}{F\left(c_{d}(r)\right)} \text { for } x \in\left[0, c_{d}(r)\right]
$$

On the other hand, if $c_{d}(r)>\xi(r)$, then Bayesian updating yields:

$$
\begin{gathered}
\widehat{F}_{N}(x)=\left\{\begin{array}{lll}
\frac{q F(x)}{q F(\xi(r))+\int_{\xi(r)}^{c_{N}(r)} p(z) d F(z)} & \text { if } \quad x \in[0, \xi(r)) \\
\frac{q F(\xi(r))+\int_{\xi(r)}^{x} p(z) d F(z)}{q F(\xi(r))+\int_{\xi(r)}^{c_{N}(r)} p(z) d F(z)} & \text { if } \quad x \in\left[\xi(r), c_{N}(r)\right]
\end{array}\right. \\
\widehat{F}_{D}(x)=\left\{\begin{array}{lll}
\frac{(1-q) F(x)}{(1-q) F(\xi(r))+\int_{\xi(r)}^{c_{D}(r)}(1-p(z)) d F(z)} & \text { if } \quad x \in[0, \xi(r)) \\
\frac{(1-q) F(\xi(r))+\int_{\xi(r)}^{x}(1-p(z)) d F(z)}{(1-q) F(\xi(r))+\int_{\xi(r)}^{c_{D}(r)}(1-p(z)) d F(z)} & \text { if } \quad x \in\left[\xi(r), c_{D}(r)\right]
\end{array}\right.
\end{gathered}
$$

With $F(\cdot)$ well-behaved, $\widehat{F}_{d}(\cdot)$ is the CDF of a non-degenerate distribution.

We can now establish $R_{2}^{*}(r \mid d)=r / q$. Given (C.1), it will be enough to prove that $\omega_{d}(r)>$ $c_{d}(r)$. The proof proceeds by contradiction. In particular, if $\omega_{d}(r) \leq c_{d}(r)$, then a type $c_{d}(r)$ borrower will choose $P 1$ if offered loan rate $R_{d}(r)$, permitting his insider an expected profit of $\Pi=p\left(c_{d}(r)\right) R_{d}(r)-r$. From Lemma 1 , we know that $\widehat{F}_{d}(\cdot)$ is not degenerate at $c_{d}(r)$ so $\omega_{d}(r) \leq c_{d}(r)$ in (C.1) implies $R_{d}(r)>r / p\left(c_{d}(r)\right)$ and, therefore, $\Pi>0$. From Proposition 2 though, $J_{2}\left(r \mid c_{d}(r), d\right)=0$ so the fact that $J_{2}(r \mid \cdot)$ is a maximum value function implies $\Pi \leq 0$. By contradiction then, $\omega_{d}(r)>c_{d}(r)$ and $\bar{R}\left(c_{d}(r)\right)<R_{2}^{*}(r \mid d)=r / q$.

To determine the value of $c_{d}(r)$, note that an insider with a type $c_{d}(r)$ borrower can make an expected profit of $p\left(c_{d}(r)\right) \bar{R}\left(c_{d}(r)\right)-r \leq J_{2}\left(r \mid c_{d}(r), d\right)=0$ by charging him 
$\bar{R}\left(c_{d}(r)\right)$. If the inequality is strict, then there exists a $\delta>0$ such that $\bar{R}\left(c_{d}(r)+\delta\right)<r / q$ and $p\left(c_{d}(r)+\delta\right) \bar{R}\left(c_{d}(r)+\delta\right)-r<0$. Therefore, the best an insider can do with a type $c_{d}(r)+\delta$ borrower is charge $R_{2}^{*}(r \mid d)=r / q$ and break even but, given that insiders only keep borrowers which yield them positive profit, this contradicts the fact that they keep all $\omega>c_{d}(r)$. In equilibrium then, $c_{D}(r)$ and $c_{N}(r)$ are implicitly defined by $p(\cdot) \bar{R}(\cdot)=r$. This is the same equation that defines $\widetilde{\omega}(r)$, implying $c_{D}(r)=c_{N}(r)=\widetilde{\omega}(r)$.

Since we now know that the insider only keeps $\omega>\widetilde{\omega}(r)$, we can restrict attention to $r<p(\omega) \bar{R}(\omega)$ in order to prove (7). Consider first $r \in(q \bar{R}(\omega), p(\omega) \bar{R}(\omega))$. From the proof of Proposition 1, we know that an informed lender would rather charge $\bar{R}(\omega)$ than $r / q$ for these policy rates. Therefore, since the insider cannot charge above the outsider offer of $R_{2}^{*}(r \mid d)=r / q$ and keep the borrower, he will charge $R_{2}^{*}(r \mid \omega, d)=\bar{R}(\omega)$ and get $J_{2}(r \mid \omega, d)=p(\omega) \bar{R}(\omega)-r>0$. Consider now $r \leq q \bar{R}(\omega)$. In this case, the outsider's offer falls below the borrower's reservation loan rate and the best the insider can do is match it, yielding $R_{2}^{*}(r \mid \omega, d)=r / q$ and $J_{2}(r \mid \omega, d)=(p(\omega)-q) r / q$. Recalling that $r \in$ $(q \bar{R}(\omega), p(\omega) \bar{R}(\omega))$ corresponds to $\omega \in(\widetilde{\omega}(r), \widehat{\omega}(r))$ and $r \leq q \bar{R}(\omega)$ corresponds to $\omega \geq$ $\widehat{\omega}(r)$ produces $R_{2}^{*}(r \mid \omega, d)$ as in $(7)$.

\section{Construction of Figure 1}

(a) Consider first $\widehat{\omega}(r)$. At $r=0$, we need $q \bar{R}(\widehat{\omega}(0))=0$ which occurs if and only if $\widehat{\omega}(0)=0$. Since $\bar{R}(\cdot)$ is increasing, $\widehat{\omega}(r)$ is increasing for $r \in(0, q \bar{R}(1))$ and equal to 1 for $r \geq q \bar{R}(1)$. Consider now $\widetilde{\omega}(r)$. Once again, $r=0$ yields $\widetilde{\omega}(0)=0$. The fact that $p(\cdot) \bar{R}(\cdot)$ is increasing implies that $\widetilde{\omega}(r)$ is increasing for $r \in(0, p(1) \bar{R}(1))$ and equal to 1 for $r \geq p(1) \bar{R}(1)$. At policy rate $r$, the set of types for which an insider charges reservation rates has length $|\widehat{\omega}(r)-\widetilde{\omega}(r)|$ (i.e., the vertical distance between the $\widehat{\omega}(r)$ and $\widetilde{\omega}(r)$ curves). Since $\omega \in(\widetilde{\omega}(r), \widehat{\omega}(r))$ if and only if $r \in(q \bar{R}(\omega), p(\omega) \bar{R}(\omega))$, the range of policy rates over which an insider charges type $\omega$ his reservation rate has length $|p(\omega) \bar{R}(\omega)-q \bar{R}(\omega)|$ (i.e., the horizontal distance between the $\widehat{\omega}(r)$ and $\widetilde{\omega}(r)$ curves). Having $p(\cdot)>q$ establishes 
$\widetilde{\omega}(r) \leq \widehat{\omega}(r)$ and having $p^{\prime}(\cdot)>0$ establishes $\frac{d}{d \omega}|p(\omega) \bar{R}(\omega)-q \bar{R}(\omega)|>0$.

(b) Consider $\eta(r)$. As before, $\eta(0)=0$ is immediate. Define:

$$
g(\omega) \equiv\left[\int_{0}^{\omega} q d F(x)+\int_{\omega}^{1} p(x) d F(x)\right] \bar{R}(\omega)
$$

Note that $q \theta_{2}=p(0) \theta_{1}$ allows us to write:

$$
g^{\prime}(\omega)=-[p(\omega)-p(0)] f(\omega) \theta_{1}+\left(\frac{p^{\prime}(\omega)[p(0)-q]}{[p(\omega)-q][p(\omega)-p(0)]}\right) g(\omega)
$$

Since $g(0)=0$ and $g(\omega)>0$ for all $\omega \in(0,1]$, it must be the case that $g^{\prime}(0)>0$. Lemma 2 establishes the sign of $g^{\prime}(\omega)$ over $\omega \in(0,1)$ under the assumptions in Subsection 3.3:

Lemma 2 Under Assumptions 1 to 3, $g(\omega)$ is monotonically increasing over $\omega \in(0,1)$.

Proof. If the claim is not true, then there must be at least one $z \in(0,1)$ such that $g^{\prime}(z)=0$. Using the expression for $g^{\prime}(\cdot)$ presented above, this $z$ is implicitly defined by $g(z)=\frac{[p(z)-q][p(z)-p(0)]^{2} f(z) \theta_{1}}{p^{\prime}(z)[p(0)-q]}$. Denoting the right side of this equation by $h(\cdot)$, we can say that $g(\cdot)$ achieves a local optimum every time it intersects $h(\cdot)$. In other words, $g^{\prime}(\cdot)$ switches signs at any $z$ such that $g(z)=h(z)$. Recalling $g^{\prime}(0)>0$, it follows that $g(\cdot)$ begins to decrease after its first intersection with $h(\cdot)$. Under the assumptions, $h^{\prime}(\cdot)>0$ and there can be no further intersections. Therefore, if there is indeed a $z \in(0,1)$ such that $g(z)=h(z)$, then we will have $g^{\prime}(1)<0$. Taken together, $g^{\prime}(1)<0$ and $f(1) \leq 1$ imply $p(0)<q+\frac{[p(1)-q]^{3}}{q p^{\prime}(1)+[p(1)-q]^{2}}$, violating Assumption 2. As a result, there cannot be a $z \in(0,1)$ such that $g(z)=h(z)$ and, by implication, $g(\cdot)$ must be monotonically increasing over $\omega \in(0,1)$.

With $g(\omega)$ increasing, the minimization problem in (13) yields only one argmin. Moreover, $\eta(r)$ is increasing for $r \in(0, q \bar{R}(1))$ and equal to 1 for $r \geq q \bar{R}(1)$. Consider now all points such that $\widetilde{\omega}(r)=\eta(r)=z$. Using the definitions of $\widetilde{\omega}(r)$ and $\eta(r)$, any such $z \in(0,1)$ must satisfy $p(z)=\left[\int_{0}^{z} q d F(\omega)+\int_{z}^{1} p(\omega) d F(\omega)\right] \equiv u(z)$. Since $u^{\prime}(\cdot)<0$, 
$p^{\prime}(\cdot)>0, u(0)>p(0)$, and $u(1)<p(1)$, we know that $p(\cdot)$ and $u(\cdot)$ intersect only once. Therefore, there is only one point such that $\eta(r)=\widetilde{\omega}(r) \in(0,1)$. Since both $\eta(r)$ and $\widetilde{\omega}(r)$ are increasing, this implies that there is only one $r \in(0, p(1) \bar{R}(1))$ such that $\eta(r)=\widetilde{\omega}(r)$. Moreover, $\eta(0)=\widetilde{\omega}(0)=0$ and $\widetilde{\omega}^{\prime}(0)=\frac{1}{p(0) \bar{R}^{\prime}(0)}>\frac{1}{u(0) \bar{R}^{\prime}(0)}=\eta^{\prime}(0)$ imply that $\eta(r)$ approaches its intersection with $\widetilde{\omega}(r)$ from below $\widetilde{\omega}(r)$.

Consider now $\xi(r)$. We can rewrite (9) as:

$$
\xi(r)=\arg \min _{\omega \in[0,1]}\left|g(\omega)-\left[r-\beta \int_{\widetilde{\omega}(r)}^{1} J_{2}(r \mid x) d F(x)\right]\right|
$$

By Lemma 2, $g^{\prime}(\omega)>0$ so this argmin is unique and $\xi(0)=0$. Furthermore, $\eta(r)$ defined as the argmin of $|g(\cdot)-r|$ and $g(1)=q \bar{R}(1)$ imply $\xi(r)<\eta(r)$ for all $r \in(0, q \bar{R}(1)]$. At $r=p(1) \bar{R}(1)$ though, $\widetilde{\omega}(r)=1$ so $\xi(r)=\eta(r)=1$. Therefore, $\xi(r)$ reaches 1 for $r \in(q \bar{R}(1), p(1) \bar{R}(1))$. Now, using Proposition 3:

$$
\int_{\widetilde{\omega}(r)}^{1} J_{2}(r \mid x) d F(x)=\int_{\widetilde{\omega}(r)}^{\widehat{\omega}(r)}[p(x) \bar{R}(x)-r] d F(x)+\int_{\widehat{\omega}(r)}^{1}\left[\frac{p(x)}{q}-1\right] r d F(x)
$$

Assumption 4 ensures that $r-\beta \int_{\widetilde{\omega}(r)}^{1} J_{2}(r \mid x) d F(x)$ is increasing in $r$ so $\xi(r)$ is also increasing until it reaches 1 . Let us now examine all policy rates such that $\xi(r)=\widetilde{\omega}(r) \in(0,1)$. Using the definitions of $\widetilde{\omega}(r)$ and $\xi(r)$, any such $r$ must satisfy:

$$
\frac{1}{p(\widetilde{\omega}(r))}\left[\int_{0}^{\widetilde{\omega}(r)} q d F(x)+\int_{\widetilde{\omega}(r)}^{1} p(x) d F(x)\right]+\beta \int_{\widetilde{\omega}(r)}^{1} \frac{J_{2}(r \mid x)}{r} d F(x)=1
$$

The first term on the left hand side is clearly decreasing in $r$. The second term is also decreasing since $\frac{d}{d r} \int_{\widetilde{\omega}(r)}^{1} \frac{J_{2}(r \mid x)}{r} d F(x)=-\int_{\widetilde{\omega}(r)}^{\widehat{\omega}(r)} \frac{p(x) \bar{R}(x)}{r^{2}} d F(x)<0$. Therefore, the left hand side $(L H S)$ is decreasing in $r$ while the right hand side $(R H S)$ is constant. Moreover, at $r=0$, we have $L H S=\infty>1=R H S$ and, at $r=p(1) \bar{R}(1)$, we have $L H S=\frac{q}{p(1)}<1=$ $R H S$. Therefore, there is a unique $r \in(0, p(1) \bar{R}(1))$ such that $\widetilde{\omega}(r)=\xi(r)$. Moreover, since $\xi(r) \leq \eta(r)$ and $\eta(r)$ is initially below $\widetilde{\omega}(r)$, we know that $\xi(r)$ also approaches its intersection with $\widetilde{\omega}(r)$ from below $\widetilde{\omega}(r)$. 
Note that Assumption 3 also identifies the curvature of $\widetilde{\omega}(r)$. Consider $r \in(0, p(1) \bar{R}(1))$. Differentiating both sides of $p(\widetilde{\omega}) \bar{R}(\widetilde{\omega})=r$ yields $\frac{d \widetilde{\omega}}{d r}=\frac{p(\widetilde{\omega})-q}{p^{\prime}(\widetilde{\omega})\left[2 p(\widetilde{\omega}) \theta_{1}-q \theta_{2}-r\right]}$ and, therefore, $\frac{d^{2} \widetilde{\omega}}{d r^{2}} \propto 2 p^{\prime}(\widetilde{\omega}) q\left[\frac{\theta_{1}-\bar{R}(\widetilde{\omega})}{2 p(\widetilde{\omega}) \theta_{1}-q \theta_{2}-r}\right]-\frac{p^{\prime \prime}(\widetilde{\omega})}{p^{\prime}(\widetilde{\omega})}[p(\widetilde{\omega})-q]$. It can be shown that $\bar{R}(\widetilde{\omega})<\theta_{1}$ so the first term in $\frac{d^{2} \widetilde{\omega}}{d r^{2}}$ is positive and, with $p^{\prime \prime}(\cdot)$ sufficiently low, $\widetilde{\omega}(r)$ is convex. A similar procedure establishes the convexity of $\widehat{\omega}(r)$ over $r \in(0, q \bar{R}(1))$. All other properties of $\widetilde{\omega}(r)$ and $\widehat{\omega}(r)$ carry over from part (a).

\section{E. Proof of Proposition 4}

I start by establishing the convexity of $\eta(r)$ and $\xi(r)$ over policy rates where these cutoffs are interior (recall that the convexity of $\widetilde{\omega}(r)$ was established in Section D). With $\eta(r)$ defined by $\left[q \eta+\int_{\eta}^{1} p(x) d x\right] \bar{R}(\eta)=r$, we have:

$$
\begin{gathered}
\frac{d \eta}{d r}=\frac{1}{-[p(\eta)-p(0)] \theta_{1}+\left[q \eta+\int_{\eta}^{1} p(x) d x\right] \bar{R}^{\prime}(\eta)} \\
\frac{d^{2} \eta}{d r^{2}}=\eta^{\prime}(r)^{3}\left(p^{\prime}(\eta) \theta_{1}+[p(\eta)-q] \bar{R}^{\prime}(\eta)-\left[q \eta+\int_{\eta}^{1} p(x) d x\right] \bar{R}^{\prime \prime}(\eta)\right)
\end{gathered}
$$

From Section D, $\eta^{\prime}(r)>0$. Moreover, $\bar{R}^{\prime \prime}(\omega) \propto p^{\prime \prime}(\omega)[p(\omega)-q]-2 p^{\prime}(\omega)^{2}$ so Assumption 3 ensures $\bar{R}^{\prime \prime}(\omega)<0$ and, thus, $\eta^{\prime \prime}(r)>0$. Turn now to $\xi(r)$. Differentiating the equation which implicitly defines $\xi(r)$ yields:

$$
\frac{d \xi}{d r}=\frac{1-\beta A^{\prime}(r)}{-[p(\xi)-q] \bar{R}(\xi)+\left[q \xi+\int_{\xi}^{1} p(x) d x\right] \bar{R}^{\prime}(\xi)}
$$

where: $A(r) \equiv \int_{\widetilde{\omega}(r)}^{\widehat{\omega}(r)}[p(x) \bar{R}(x)-r] d x+\int_{\widehat{\omega}(r)}^{1}\left[\frac{p(x)}{q}-1\right] r d x$

After some algebra, we get that the second derivative satisfies:

$$
\frac{d^{2} \xi}{d r^{2}} \propto-\beta A^{\prime \prime}(r)+\left[p^{\prime}(\xi) \bar{R}(\xi)+2[p(\xi)-q] \bar{R}^{\prime}(\xi)-\left[q \xi+\int_{\xi}^{1} p(x) d x\right] \bar{R}^{\prime \prime}(\xi)\right] \xi^{\prime}(r)^{2}
$$


Since $\bar{R}^{\prime \prime}(\cdot)<0$, a sufficient condition for $\xi^{\prime \prime}(r)>0$ is $A^{\prime \prime}(r)<0$. With $p(\cdot)>q$ and $A^{\prime \prime}(r)=\widetilde{\omega}^{\prime}(r)-\frac{p(\widehat{\omega}(r))}{q} \widehat{\omega}^{\prime}(r)$, this sufficient condition is guaranteed by $\widetilde{\omega}^{\prime}(r)<\widehat{\omega}^{\prime}(r)$. Note that $\widetilde{\omega}^{\prime}(r)<\widehat{\omega}^{\prime}(r)$ is equivalent to $p^{\prime}(\widetilde{\omega}) \bar{R}(\widetilde{\omega})+p(\widetilde{\omega}) \bar{R}^{\prime}(\widetilde{\omega})>q \bar{R}^{\prime}(\widehat{\omega})$, which is certainly true since $\widetilde{\omega} \leq \widehat{\omega}$ and $\bar{R}^{\prime \prime}(\cdot)<0$ imply that $\bar{R}^{\prime}(\widetilde{\omega})>\bar{R}^{\prime}(\widehat{\omega})$. Thus, $A^{\prime \prime}(r)<0$ and $\xi^{\prime \prime}(r)>0$.

Turn now to the relevance of these results for steady state smoothness. That $\eta(r)$ is an increasing and convex function of $r$ yields:

$$
\begin{gathered}
Y_{S}^{\prime}(r)=-[p(1)-p(0)] \theta_{1} \eta(r) \eta^{\prime}(r)<0 \\
Y_{S}^{\prime \prime}(r)=-[p(1)-p(0)] \theta_{1}\left[\eta^{\prime}(r)^{2}+\eta(r) \eta^{\prime \prime}(r)\right]<0
\end{gathered}
$$

Moreover, since $\xi(r)$ and $\widetilde{\omega}(r)$ are also increasing and convex, we have:

$$
\begin{gathered}
Y^{\prime}(r)=-[p(1)-p(0)] \theta_{1}\left[\frac{\mu}{1+\mu} \xi(r) \xi^{\prime}(r)+\frac{1}{1+\mu} \widetilde{\omega}(r) \widetilde{\omega}^{\prime}(r)\right]<0 \\
Y^{\prime \prime}(r)=-[p(1)-p(0)] \theta_{1}\left[\frac{\mu}{1+\mu}\left[\xi^{\prime}(r)^{2}+\xi(r) \xi^{\prime \prime}(r)\right]+\frac{1}{1+\mu}\left[\widetilde{\omega}^{\prime}(r)^{2}+\widetilde{\omega}(r) \widetilde{\omega}^{\prime \prime}(r)\right]\right]<0
\end{gathered}
$$

The concavity of $Y_{S}(r)$ and $Y(r)$ simplifies the smoothness measure. In particular, if $y(r)$ is a concave function, we can write:

$$
S=-\int_{a}^{b} y^{\prime \prime}(r) d r=-\left[y^{\prime}(b)-y^{\prime}(a)\right]
$$

The right-hand side limits of $Y^{\prime}(0)$ and $Y_{S}^{\prime}(0)$ are both zero so establishing the desired smoothness result amounts to establishing $Y^{\prime}(q \bar{R}(1))>Y_{S}^{\prime}(q \bar{R}(1))$. Consider first $\mu=0$. In this case, we want to establish $\widetilde{\omega}(q \bar{R}(1)) \widetilde{\omega}^{\prime}(q \bar{R}(1))<\eta(q \bar{R}(1)) \eta^{\prime}(q \bar{R}(1))$. Using $\eta(q \bar{R}(1))=1$ and the derivatives presented earlier, this amounts to showing:

$$
\frac{\widetilde{\omega}(q \bar{R}(1))}{\left[\frac{p(1)-p(0)}{p(\widetilde{\omega})-q}\right] \widetilde{\omega}+p(\widetilde{\omega}) \frac{[p(0)-q]}{[p(\widetilde{\omega})-q]^{2}}}<\frac{1}{-1+q \frac{[p(0)-q]}{[p(1)-q]^{2}}}
$$

A sufficient condition for the preceding to be true is $\frac{q}{[p(1)-q]^{2}}<\frac{p(\widetilde{\omega})}{[p(\widetilde{\omega})-q]^{2}}$, which is guaranteed 
by $p(1)>p(\widetilde{\omega})>q$. Therefore, for $\mu=0, Y(r)$ is smoother than $Y_{S}(r)$. Since $\mu=0$ puts all the weight on $Y_{k \geq 3}(r)$ in the calculation of $Y(r)$, we can conclude that $Y_{k \geq 3}(r)$ is smoother than $Y_{S}(r)$. As $\mu$ increases, weight shifts from $Y_{k \geq 3}(r)$ to $Y_{1}(r)$ so, to show that $Y(r)$ is smoother than $Y_{S}(r)$ for all $\mu$, it will be enough to show that $Y(r)$ is smoother than $Y_{S}(r)$ for $\mu=1$. In this case, what we want to establish is:

$$
\xi(q \bar{R}(1)) \xi^{\prime}(q \bar{R}(1))+\widetilde{\omega}(q \bar{R}(1)) \widetilde{\omega}^{\prime}(q \bar{R}(1))<2 \eta(q \bar{R}(1)) \eta^{\prime}(q \bar{R}(1))
$$

Substituting in the derivatives (and suppressing the argument $r$ ), the above inequality becomes:

$$
\begin{aligned}
& \frac{\xi(1+\beta[1-\widetilde{\omega}])}{[p(1)-p(0)] \theta_{1}\left(-\xi+\left[q \xi+\int_{\xi}^{1} p(x) d x\right] \frac{[p(0)-q]}{[p(\xi)-q]^{2}}\right)} \\
& \quad+\frac{\widetilde{\omega}}{p^{\prime}(\widetilde{\omega}) \bar{R}(\widetilde{\omega})+p(\widetilde{\omega}) \bar{R}^{\prime}(\widetilde{\omega})}<\frac{2}{[p(1)-p(0)] \theta_{1}\left(-1+q \frac{[p(0)-q]}{[p(1)-q]^{2}}\right)}
\end{aligned}
$$

A sufficient condition can be established by noting the following:

$$
\frac{\xi(1+\beta[1-\widetilde{\omega}])}{[p(1)-p(0)] \theta_{1}\left(-\xi+\left[q \xi+\int_{\xi}^{1} p(x) d x\right] \frac{[p(0)-q]}{[p(\xi)-q]^{2}}\right)}<\frac{2-\widetilde{\omega}}{[p(1)-p(0)] \theta_{1}\left(-1+q \frac{[p(0)-q]}{[p(1)-q]^{2}}\right)}
$$

In particular, substituting this upper bound into (E.1) and rearranging yields the sufficient condition below:

$$
[p(1)-p(0)] \theta_{1}\left(-1+q \frac{[p(0)-q]}{[p(1)-q]^{2}}\right)<p^{\prime}(\widetilde{\omega}) \bar{R}(\widetilde{\omega})+p(\widetilde{\omega}) \bar{R}^{\prime}(\widetilde{\omega})
$$

Replacing $\bar{R}(\widetilde{\omega})$ and $\bar{R}^{\prime}(\widetilde{\omega})$ with the appropriate expressions, the sufficient condition then becomes: 


$$
q \frac{[p(0)-q]}{[p(1)-q]^{2}}<1+\frac{[p(\widetilde{\omega})-p(0)]}{p(\widetilde{\omega})-q}+p(\widetilde{\omega}) \frac{[p(0)-q]}{[p(\widetilde{\omega})-q]^{2}}
$$

This inequality is certainly satisfied if $\frac{q}{[p(1)-q]^{2}}<\frac{p(\widetilde{\omega})}{[p(\widetilde{\omega})-q]^{2}}$, which is again guaranteed by $p(1)>p(\widetilde{\omega})>q$. Therefore, $Y(r)$ is smoother than $Y_{S}(r)$ when smoothness is defined according to $S$.

Consider now $\widehat{S}$. For a decreasing function $y(r)$, we can write:

$$
\widehat{S}=-\int_{a}^{b} y^{\prime}(r) d r=-[y(b)-y(a)]
$$

Since $Y(0)=Y_{S}(0)$, establishing that $Y(r)$ is smoother than $Y_{S}(r)$ when smoothness is defined according to $\widehat{S}$ amounts to establishing $Y(q \bar{R}(1))>Y_{S}(q \bar{R}(1))$. A sufficient condition is $\max \{\widetilde{\omega}(q \bar{R}(1)), \xi(q \bar{R}(1))\}<\eta(q \bar{R}(1))=1$, which was shown to be true in Section D.

\section{F. Proof of Proposition 5}

Suppose an unexpected shock hits at $t=1$ (i.e., $\varepsilon_{1} \neq 0$ but $\varepsilon_{t}=0$ for all $t>1$ ) and an additional $T-1$ periods are required for the policy rate to return to its steady state value. Without relationship lending, output at time $t$ is just $Y_{S}\left(r_{t}\right)$, where $Y_{S}(\cdot)$ is as defined in (14). The variance of the transition path relative to steady state in the standard credit model is thus:

$$
\sigma_{S}^{2} \equiv \frac{1}{T} \sum_{t=1}^{T}\left[Y_{S}\left(r_{t}\right)-Y_{S}\left(r_{s s}\right)\right]^{2}
$$

The analogous measure for the model with relationship lending is:

$$
\sigma_{R}^{2} \equiv \frac{1}{T} \sum_{t=1}^{T}\left[Y_{t}\left(r_{t}\right)-Y\left(r_{s s}\right)\right]^{2}
$$

Note that $Y_{t}\left(r_{t}\right)$ is not necessarily equal to $Y\left(r_{t}\right)$. In addition to the current cost of funds, 
first period output depends on expectations of future relationship profits and, therefore, expectations of future policy rates. With $r_{t+1}=r_{s s}+\alpha\left(r_{s s}-r_{t}\right)$ for $t \geq 1$, the appropriate first period cutoff at time $t$ is:

$$
\xi_{t} \equiv \arg \min _{\omega \in[0,1]}\left|\left[q \omega+\int_{\omega}^{1} p(x) d x\right] \bar{R}(\omega)+\beta \int_{\widetilde{\omega}\left(r_{t+1}\right)}^{1} J_{2}\left(r_{t+1} \mid x\right) d x-r_{t}\right|
$$

Expected relationship profits equal $\int_{\widetilde{\omega}(r)}^{1} J_{2}(r \mid x) d x$ and, at high policy rates, this expression is decreasing in $r$. If $\varepsilon_{1}>0$, then $r_{t+1}<r_{t}$ for all $t \geq 1$ and, therefore, $\int_{\widetilde{\omega}\left(r_{t+1}\right)}^{1} J_{2}\left(r_{t+1} \mid x\right) d x>$ $\int_{\widetilde{\omega}\left(r_{t}\right)}^{1} J_{2}\left(r_{t} \mid x\right) d x$. We know from Lemma 2 that $\left[q \omega+\int_{\omega}^{1} p(x) d x\right] \bar{R}(\omega)$ is increasing in $\omega$ so it must be the case that $\xi_{t}<\xi\left(r_{t}\right)$, where $\xi(\cdot)$ is as defined in (9). In other words, $Y_{t}\left(r_{t}\right)>$ $Y\left(r_{t}\right)$. Since $\varepsilon_{1}>0$ yields policy rates that are always above $r_{s s}$ along the transition path, we can further conclude that $Y\left(r_{s s}\right)>Y_{t}\left(r_{t}\right)>Y\left(r_{t}\right)$ and thus $\sigma_{R}^{2}<\frac{1}{T} \sum_{t=1}^{T}\left[Y\left(r_{t}\right)-Y\left(r_{s s}\right)\right]^{2}$. If instead $\varepsilon_{1}<0$, a similar argument establishes $Y\left(r_{s s}\right)<Y_{t}\left(r_{t}\right)<Y\left(r_{t}\right)$ and, once again, $\sigma_{R}^{2}<\frac{1}{T} \sum_{t=1}^{T}\left[Y\left(r_{t}\right)-Y\left(r_{s s}\right)\right]^{2}$.

A sufficient condition for $\sigma_{R}^{2}<\sigma_{S}^{2}$ is then $\sum_{t=1}^{T}\left[Y\left(r_{t}\right)-Y\left(r_{s s}\right)\right]^{2}<\sum_{t=1}^{T}\left[Y_{S}\left(r_{t}\right)-Y_{S}\left(r_{s s}\right)\right]^{2}$ and, since $r_{t} \in\left[\min \left\{r_{s s}, r_{1}\right\}, \max \left\{r_{s s}, r_{1}\right\}\right] \equiv \mathbf{r}$ along the transition path, having $\left|Y^{\prime}(\cdot)\right|<$ $\left|Y_{S}^{\prime}(\cdot)\right|$ over this interval would guarantee it. Recalling the expressions for $Y^{\prime}(r)$ and $Y_{S}^{\prime}(r)$ from the proof of Proposition 4, what we would like to show is:

$$
\frac{\mu}{1+\mu} \xi(r) \xi^{\prime}(r)+\frac{1}{1+\mu} \widetilde{\omega}(r) \widetilde{\omega}^{\prime}(r)<\eta(r) \eta^{\prime}(r)
$$

Consider first $\mu=0$. Since $\widetilde{\omega}(r)<\eta(r)$ for large values of $r$, it will be enough to show that $\widetilde{\omega}^{\prime}(r)<\eta^{\prime}(r)$ or, equivalently:

$$
-\eta+\left[q \eta+\int_{\eta}^{1} p(x) d x\right] \frac{[p(0)-q]}{[p(\eta)-q]^{2}}<\left[\frac{p(1)-p(0)}{p(\widetilde{\omega})-q}\right] \widetilde{\omega}+p(\widetilde{\omega}) \frac{[p(0)-q]}{[p(\widetilde{\omega})-q]^{2}}
$$

A sufficient condition for the above inequality is $q \eta+\int_{\eta}^{1} p(x) d x<p(\widetilde{\omega})$. To see that this is indeed true, recall $\left[q \eta+\int_{\eta}^{1} p(x) d x\right] \bar{R}(\eta)=r=p(\widetilde{\omega}) \bar{R}(\widetilde{\omega})$ and $\bar{R}^{\prime}(\cdot)>0$. With $\widetilde{\omega}<\eta$, 
we have $\bar{R}(\widetilde{\omega})<\bar{R}(\eta)$ and, thus, $q \eta+\int_{\eta}^{1} p(x) d x<p(\widetilde{\omega})$. We can now conclude that $\left|Y^{\prime}(r)\right|<\left|Y_{S}^{\prime}(r)\right|$ for $r \in \mathbf{r}$ when $\mu=0$.

Note that $\mu=0$ puts all the weight on $Y_{k \geq 3}(r)$ so what we have just shown is that $Y_{k \geq 3}(r)$ is flatter than $Y_{S}(r)$ for $r \in \mathbf{r}$. As $\mu$ increases, weight shifts from $Y_{k \geq 3}(r)$ to $Y_{1}(r)$. Since $Y_{k \geq 3}(r)$ is assigned the smallest weight when $\mu=1$, it will be enough to show that $\left|Y^{\prime}(r)\right|<\left|Y_{S}^{\prime}(r)\right|$ for $r \in \mathbf{r}$ under $\mu=1$ in order to show that $\left|Y^{\prime}(r)\right|<\left|Y_{S}^{\prime}(r)\right|$ for $r \in \mathbf{r}$ under any $\mu$.

Consider then $\mu=1$. What we want to show now is $\xi(r) \xi^{\prime}(r)+\widetilde{\omega}(r) \widetilde{\omega}^{\prime}(r)<2 \eta(r) \eta^{\prime}(r)$. To do so, define $h(\omega) \equiv-\omega+\left[q \omega+\int_{\omega}^{1} p(x) d x\right] \frac{[p(0)-q]}{[p(\omega)-q]^{2}}$ and rewrite $\eta^{\prime}(r)$ and $\xi^{\prime}(r)$ as:

$$
\begin{gathered}
\eta^{\prime}(r)=\frac{1}{[p(1)-p(0)] \theta_{1} h(\eta)} \\
\xi^{\prime}(r)=\frac{1+\beta[1-\widetilde{\omega}]-\beta \int_{\widetilde{\omega}}^{1} \frac{p(x)}{q} d x}{[p(1)-p(0)] \theta_{1} h(\xi)}<\frac{2-\widetilde{\omega}}{[p(1)-p(0)] \theta_{1} h(\xi)}
\end{gathered}
$$

Since $h^{\prime}(\cdot)<0$ and $\xi<\eta$, we know that $h(\xi)>h(\eta)$ and, therefore, $\xi^{\prime}(r)<\frac{2-\widetilde{\omega}}{[p(1)-p(0)] \theta_{1} h(\eta)}$. A sufficient condition for what we currently want to show is thus $\widetilde{\omega}^{\prime}(r)<\frac{\eta}{[p(1)-p(0)] \theta_{1} h(\eta)}$. Substituting in for $\widetilde{\omega}^{\prime}(r)$, this sufficient condition becomes:

$$
\frac{1}{\frac{p(\widetilde{\omega})-p(0)}{p(\widetilde{\omega})-q}+p(\widetilde{\omega}) \frac{[p(0)-q]}{[p(\widetilde{\omega})-q]^{2}}}<\frac{\eta}{-\eta+\left[q \eta+\int_{\eta}^{1} p(x) d x\right] \frac{[p(0)-q]}{[p(\eta)-q]^{2}}}
$$

Recall that $p(\widetilde{\omega}) \bar{R}(\widetilde{\omega})=\left[q \eta+\int_{\eta}^{1} p(x) d x\right] \bar{R}(\eta)$ and, under $p(\cdot)$ linear, $\bar{R}(\omega)=\frac{[p(1)-p(0)] \theta_{1} \omega}{p(\omega)-q}$. Combining these equations yields $q \eta+\int_{\eta}^{1} p(x) d x=p(\widetilde{\omega}) \frac{\widetilde{\omega}[p(\eta)-q]}{\eta[p(\widetilde{\omega})-q]}$ and lets us write (F.1) as:

$$
-1+p(\widetilde{\omega})\left(\frac{p(0)-q}{p(\widetilde{\omega})-q}\right)\left[\frac{\widetilde{\omega}}{\eta^{2}} \frac{1}{[p(\eta)-q]}-\frac{1}{[p(\widetilde{\omega})-q]}\right]<\frac{p(\widetilde{\omega})-p(0)}{p(\widetilde{\omega})-q}
$$

With $0<\widetilde{\omega}<\eta$, a sufficient condition for the preceding inequality is $p(\widetilde{\omega})\left[\frac{1}{\eta}-1\right]<$ $2 p(\widetilde{\omega})-p(0)-q$ or, equivalently, $\eta>\frac{p(\widetilde{\omega})}{3 p(\widetilde{\omega})-p(0)-q}$. In other words, (F.1) is guaranteed for $\eta$ sufficiently large. Since $\eta^{\prime}(r)>0$, it then follows that (F.1) is guaranteed for $r$ sufficiently large. 


\section{Supplementary Appendix: An Extension with Distributional Dynamics}

The results of the main text suggest that, on average, the informational properties of relationship lending lead to improved credit terms. In reality though, borrowers with improved terms may be better able to overcome adverse idiosyncratic events that would have otherwise put them out of business. Along with learning then, relationship lending may also foster lower firm exit rates. To understand the implications of this possibility, I extend the baseline model. In particular, as long as a borrower stays with his insider, he experiences exogenous separation with probability $\mu-\varepsilon$, where $\varepsilon>0$. If or once he switches to an outsider, separation occurs with probability $\mu$.

As noted in Subsection 6.2, the difference in separation rates has two important implications. First, it gives insiders more bargaining power over high types so insiders can now charge slightly above the outsider offer without losing these borrowers. Second, it provides a new source of transition dynamics by making the policy rate affect the distribution of borrowers across periods. In this appendix, I set up the extended model more formally.

\section{Value Functions}

Outsiders still compete against each other and make zero expected profits so their $k \geq 3$ and $k=2$ value functions are of the same form as those in Subsections 3.1 and 3.2. In contrast, the $k=2$ value function of an insider is now:

$$
J_{2, I}(r \mid \omega, d)=\max \left\{0,\left\{\begin{array}{cl}
\max _{R} & \bar{\gamma}(R \mid \omega) R-r+\beta(1-\mu+\varepsilon) J_{k \geq 3, I}(r \mid \omega) \\
\text { s.t. } & V_{2, I}(\omega \mid R) \geq V_{2, U}\left(\omega \mid R_{2, U, d}\right)
\end{array}\right\}\right\}
$$

where $V_{2, I}(\omega \mid R)$ is the value of a second-time type $\omega$ borrower who stays with his insider and pays loan rate $R$ while $V_{2, U}\left(\omega \mid R_{2, U, d}\right)$ is the value of this borrower should he move to an outsider charging $R_{2, U, d}$. The insider's value function for any $k \geq 3$ is also given by the right hand side of (S.1) but with $V_{k \geq 3, I}(\omega \mid R) \geq V_{k \geq 3, U}\left(\omega \mid R_{k \geq 3, U, \omega}\right)$ as the borrower's participation constraint.

For the baseline model (i.e., $\varepsilon=0$ ), it was proven that second-time borrowers are not divided according to default history. In the absence of an analytical solution for the extended model, there is no presumption that this is still the case. Therefore, second period loan rates are not restricted to be history-independent and the first period borrower strategy is now denoted by $\bar{\gamma}_{1}(R \mid \omega)$ to distinguish it from $\bar{\gamma}(R \mid \omega)$. The value function of a first period lender is then similar to equation (8) in the main text except that $\bar{\gamma}_{1}(\cdot)$ is used instead of $\bar{\gamma}(\cdot)$ and expected future profits are determined using (S.1) and the market splitting that results. 
Consider now the borrower side. For a first-time borrower facing loan rate $R$, the expected payoffs associated with choosing $P 1$ and $P 2$ are given by (S.2) and (S.3) respectively:

$$
\begin{aligned}
& p(\omega)\left[\theta_{1}-R+\beta V_{2}\left(\omega \mid R_{2, I, N}, R_{2, U, N}\right)\right]+(1-p(\omega)) \beta V_{2}\left(\omega \mid R_{2, I, D}, R_{2, U, D}\right) \\
& q\left[\theta_{2}-R+\beta V_{2}\left(\omega \mid R_{2, I, N}, R_{2, U, N}\right)\right]+(1-q) \beta V_{2}\left(\omega \mid R_{2, I, D}, R_{2, U, D}\right)
\end{aligned}
$$

where $V_{2}\left(\omega \mid R_{2, I, d}, R_{2, U, d}\right)=\max \left\{V_{2, I}\left(\omega \mid R_{2, I, d}\right), V_{2, U}\left(\omega \mid R_{2, U, d}\right)\right\}$ is the borrower's second period value function. His first period value, $V_{1}(\omega \mid R)$, is given by the maximum of (S.2) and (S.3) and his strategy is $\bar{\gamma}_{1}(R \mid \omega)=p(\omega)$ if and only if (S.2) is greater than (S.3). Finally, to determine $V_{2}\left(\omega \mid R_{2, I, d}, R_{2, U, d}\right)$, note that:

$$
\begin{aligned}
V_{2, I}(\omega \mid R)=V_{k \geq 3, I}(\omega \mid R)= & \max \left\{p(\omega)\left[\theta_{1}-R\right], q\left[\theta_{2}-R\right]\right\}+\beta(\mu-\varepsilon) \int_{0}^{1} V_{1}\left(x \mid R_{1}\right) d F(x) \\
+ & \beta(1-\mu+\varepsilon) \max \left\{V_{k \geq 3, I}\left(\omega \mid R_{k \geq 3, I, \omega}\right), V_{k \geq 3, U}\left(\omega \mid R_{k \geq 3, U, \omega}\right)\right\} \\
V_{2, U}(\omega \mid R)=V_{k \geq 3, U}(\omega \mid R)= & \max \left\{p(\omega)\left[\theta_{1}-R\right], q\left[\theta_{2}-R\right]\right\}+\beta \mu \int_{0}^{1} V_{1}\left(x \mid R_{1}\right) d F(x) \\
& +\beta(1-\mu) V_{k \geq 3, U}\left(\omega \mid R_{k \geq 3, U, \omega}\right)
\end{aligned}
$$

\section{Transition Dynamics}

Suppose an unanticipated permanent increase in $r$ occurs at date $t$. Lenders with advanced borrowers can adjust immediately to the new steady state but this may not be true for lenders with intermediate borrowers. Recall that the only piece of information available to a second period outsider is whether the borrower defaulted on his first period loan and, at date $t$, this outcome depends on loan rates induced by the $t-1$ policy rate. In the insider's problem, however, expected future profits depend on loan rates induced by the $t+1$ policy rate. Since an equilibrium is reached when each lender's offer is a best response to the other's, the second period loan rates that prevail at date $t$ depend on both pre-shock and post-shock policy rates. In contrast, the post-shock steady state is conditioned entirely on the post-shock policy rate so the $k=2$ equilibrium at date $t$ may differ from the new $k=2$ steady state.

To determine how long it takes to reach the new steady state, consider the market for new borrowers. If first period lenders at date $t$ expect a full adjustment by date $t+1$, then they will adjust immediately. As a result, both outsider information and insider profits at date $t+1$ will be conditioned on the new policy rate. This means that the $k=2$ equilibrium will reach the new steady state by date $t+1$, consistent with the time $t$ expectations of first period lenders. In what follows, I focus on this case. That is, all contracts adjust to the new steady state by date $t+1 .^{19}$ Note, however, that even with a quick contract response, the

\footnotetext{
${ }^{19}$ Other assumptions about the time it takes for contracts to adjust would be ad hoc at this point. Issues of contract stickiness are thus left for future work.
} 
effects of the policy rate shock continue to be propagated through the distribution. We can see this by formalizing the borrower flows. Let $I_{2, d, t}(\omega)$ be an indicator function that equals 1 if a second-time borrower with type $\omega$ and default history $d$ stays with his insider at date $t$. Similarly, define $I_{k \geq 3, t}(\omega)$ so that $I_{k \geq 3, t}(\omega)=1$ if $V_{k \geq 3, I}\left(\omega \mid R_{k \geq 3, I, \omega, t}\right) \geq V_{k \geq 3, U}\left(\omega \mid R_{k \geq 3, U, \omega, t}\right)$. The mass of $k=1$ borrowers at date $t+1$ is now:

$$
\Psi_{1, t+1}=(\mu-\varepsilon) \int_{0}^{1}\left[\psi_{2, I, t}(x)+\psi_{k \geq 3, I, t}(x)\right] d x+\mu \int_{0}^{1}\left[\psi_{2, U, t}(x)+\psi_{k \geq 3, U, t}(x)\right] d x
$$

where $\psi_{2, I, t}(\cdot)$ is the distribution of borrower types across $k=2$ insiders and $\psi_{2, U, t}(\cdot)$ is the distribution of borrower types across $k=2$ outsiders. The corresponding distributions for $k \geq 3$ are denoted by $\psi_{k \geq 3, I, t}(\cdot)$ and $\psi_{k \geq 3, U, t}(\cdot)$. The laws of motion for these distributions are as follows:

$$
\begin{gathered}
\psi_{2, I, t+1}(\omega)=\Psi_{1, t}\left[\begin{array}{l}
\bar{\gamma}_{1}\left(R_{1, t} \mid \omega\right) I_{2, N, t+1}(\omega) \\
+\left[1-\bar{\gamma}_{1}\left(R_{1, t} \mid \omega\right)\right] I_{2, D, t+1}(\omega)
\end{array}\right] \\
\psi_{2, U, t+1}(\omega)=\Psi_{1, t}\left[\begin{array}{l}
\bar{\gamma}_{1}\left(R_{1, t} \mid \omega\right)\left[1-I_{2, N, t+1}(\omega)\right] \\
+\left[1-\bar{\gamma}_{1}\left(R_{1, t} \mid \omega\right)\right]\left[1-I_{2, D, t+1}(\omega)\right]
\end{array}\right] \\
\psi_{k \geq 3, I, t+1}(\omega)=(1-\mu+\varepsilon)\left[\psi_{2, I, t}(\omega)+\psi_{k \geq 3, I, t}(\omega)\right] I_{k \geq 3, t+1}(\omega) \\
\psi_{k \geq 3, U, t+1}(\omega)=\left[\begin{array}{l}
(1-\mu)\left[\psi_{2, U, t}(\omega)+\psi_{k \geq 3, U, t}(\omega)\right] \\
+(1-\mu+\varepsilon)\left[\psi_{2, I, t}(\omega)+\psi_{k \geq 3, I, t}(\omega)\right]\left[1-I_{k \geq 3, t+1}(\omega)\right]
\end{array}\right]
\end{gathered}
$$

Shocks to the policy rate affect the terms offered by various lenders and changes in these terms then affect which borrowers choose to stay with their insiders (i.e., $I_{2, N}, I_{2, D}$, and $I_{k \geq 3}$ respond). When $\varepsilon$ is positive, types that stay with their insiders become more persistent so changes in $r$ alter the distribution of borrower types in and across periods. As these distributions evolve to their new steady states, aggregate dynamics are observed well beyond time $t$.

\section{Numerical Analysis}

To compute the equilibrium quantities, discretize the type space and the set of possible loan rates and initialize the loan rate functions and the value functions. Given the loan rates, I determine the borrowers' strategies by iterating on their value functions then, based on these strategies, I iterate on the loan rates to find the optimal lender responses. The equilibrium is determined by iterating on the outer loop until the starting and ending loan rate functions converge. 
To execute the iterations, I set $\beta=0.96$ and use a uniform distribution of types. Returns are $\theta_{1}=5$ and $\theta_{2}=6$ so that the speculative project yields 20 percent more than the investment project if successful. The probability of success for the investment project is assumed to be linear in borrower type, satisfying $p(\omega)=p(0)+[p(1)-p(0)] \omega$. By definition, the best type is very likely to succeed if he operates $P 1$ so I set $p(1)=0.9$. The success rate of the speculative project is much lower but, since it still needs to be a legitimate outside option, I consider $q=0.65$. With values for $q, \theta_{1}$, and $\theta_{2}$, we can then use $p(0) \theta_{1}=q \theta_{2}$ to pin down $p(0)=0.78$. Unless otherwise specified, $\mu=0.3$ and $\varepsilon=0.065$.

\section{Steady State}

Figure S.1 illustrates steady state results for the extended model. The aggregate output profile resembles that in the main text but, by making better types more persistent, higher values of $\varepsilon$ shift the profile upwards. There are two additional differences relative to the baseline model. First and as shown in Figure S.1(a), the steady state measure of relationship lending exhibits a hump-shaped response to increases in the policy rate instead of a monotonic decline. Second and as shown in Figure S.1(b), credit history matters even though the insider still discovers his borrower's type with certainty (i.e., $\phi=1$ ).

A higher policy rate increases the cost of lending so, all else constant, the lowest type on which the insider breaks even rises. As before then, insiders become more selective in their retention of borrowers and fewer lending relationships are formed. Now, however, the additional bargaining power that $\varepsilon$ gives the insider over better types means that more of the necessary break even can be accommodated by increases in the loan rate, stemming the restriction of insider credit. The bargaining power effect plays out initially but is eventually dominated by the selectivity effect, leading to the hump-shaped response in relationship lending.

The bargaining and selectivity effects are also useful for understanding why credit history can matter with $\varepsilon>0$. At higher policy rates, the increase in insider selectivity means that more types have to resort to outsider credit. This increases outsider uncertainty and makes credit history a natural screening mechanism. The informativeness of credit history, however, depends on the first period loan rate. In particular, a very high $R_{1}$ induces most types to choose $P \mathscr{2}$ in the first period and implies high default probabilities across the board. The opposite is true when $R_{1}$ is very low. Therefore, by getting good firms to choose $P 1$ and bad firms to choose $P$ Q , moderate first period loan rates generate the most informative credit histories. For credit history to matter then, we need a relatively high value of $r$ but a relatively moderate value of $R_{1}$. This configuration can be achieved under $\varepsilon>0$ since the bargaining power afforded to insiders over high types increases the expectation of future 
profits and, for any $r$, competitive first period lenders settle on an even lower value of $R_{1}$. To be sure, adverse selection still arises with $\varepsilon>0$ but, for relatively high policy rates, the informativeness of credit history is such that $d$ cannot be completely crowded out.

\section{Dynamics}

Consider now the transition between steady states after an increase in the policy rate at date $t$. As shown in Figure S.2, the initial response of relationship lending tends to overshoot its new steady state value. To see why, define the extensive margin in period $k$ as the total number of borrowers in that period and the intensive margin as the proportion of these borrowers that enter into multi-period lending relationships. The extent of relationship lending in any given period is approximately equal to the product of its intensive and extensive margins. ${ }^{20}$ The extent of relationship lending at any given date is then equal to the sum of the extents for periods 2 and above. The right panel of Figure S.1(c) reveals that $k=2$ is critical for the analysis. When $r$ increases from 0.5 to 0.75 , the bargaining power effect drives up the second period intensive margin and we observe the immediate increase in relationship lending shown in Figure S.2(a). Over time though, more lending relationships mean fewer exogenous separations so the distribution of borrowers eventually shifts away from $k=2$ and the extent of relationship lending declines along the transition path. Therefore, the increase in relationship lending overshoots its new steady state and the decrease in output undershoots. As set up in Subsection 4.5, the standard model adjusts to its new steady state immediately so the results presented here suggest that relationship lending leads to a more gradual transition after certain permanent shocks. ${ }^{21}$

In comparison, Figure S.2(b) demonstrates that an increase in the policy rate from 0.75 to 1 causes the decrease in output to overshoot. For this range of $r$, the insider's selectivity effect dominates, pushing the second period intensive margin back down. As the immediate decrease in relationship lending eventually increases the number of young borrowers (i.e., the pool of potential relationship borrowers), the initial declines in relationship lending and output are partially offset over time. Even at its trough, however, aggregate output in Figure S.2(b) exceeds the standard credit model's new steady state of $Y_{S}(1) \approx 4.16$.

\footnotetext{
${ }^{20}$ The result is an approximation for the second period since it aggregates across default histories.

${ }^{21}$ This is not to say that traditional models do not generate dynamics. Instead, the transitions presented here should be interpreted as dynamics over and above those generated by a model that ignores relationship lending.
} 
Figure S.1: Steady state results in the extended model

(a) Aggregate output and relationship lending
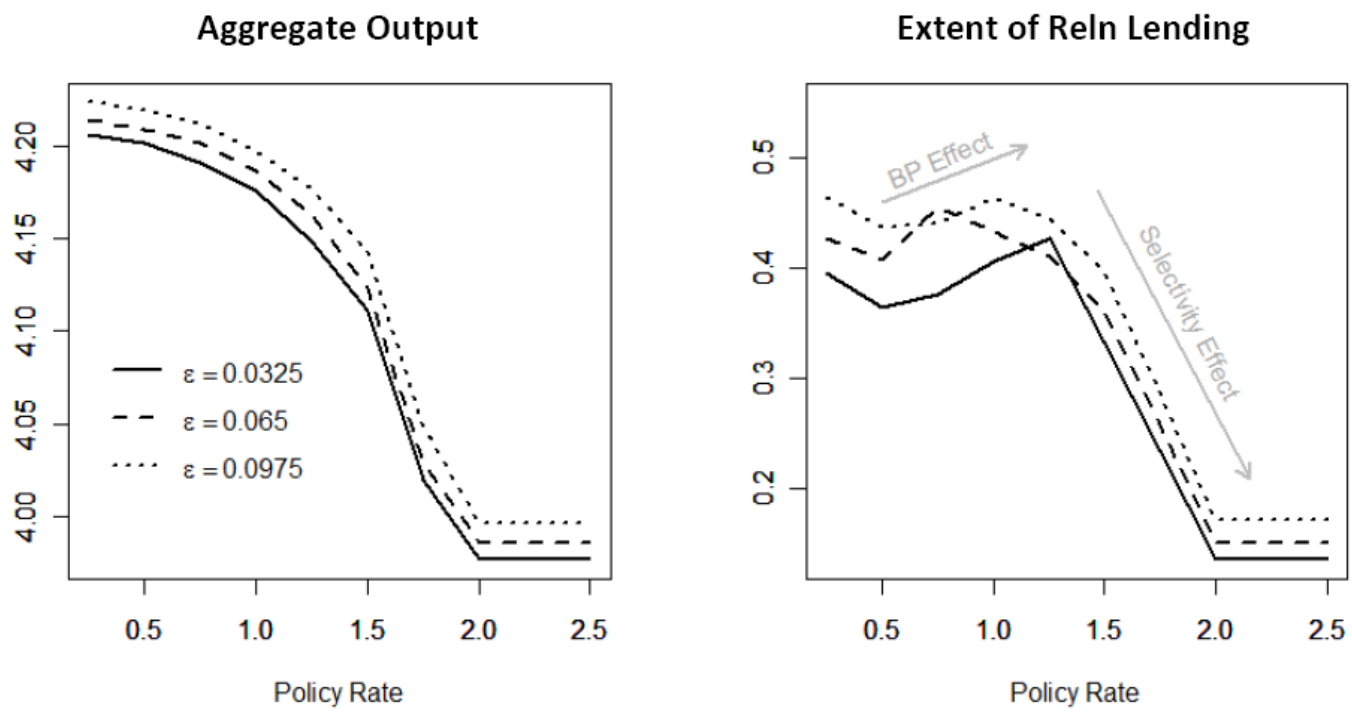

(b) Realized second period loan rates
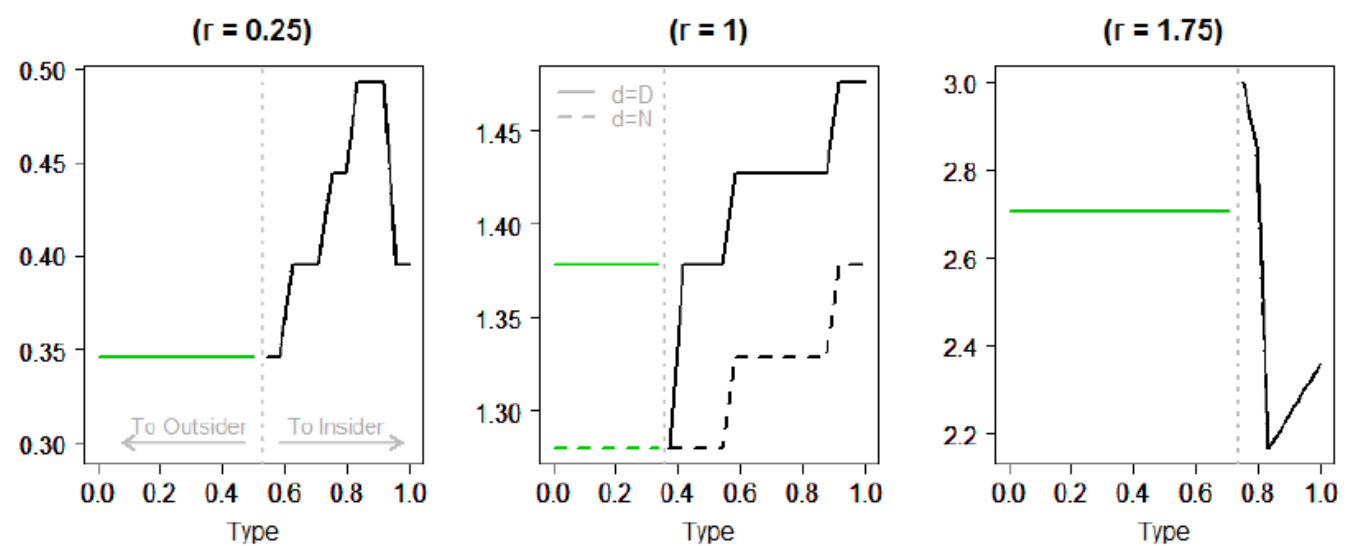

(c) Intensive and extensive margins
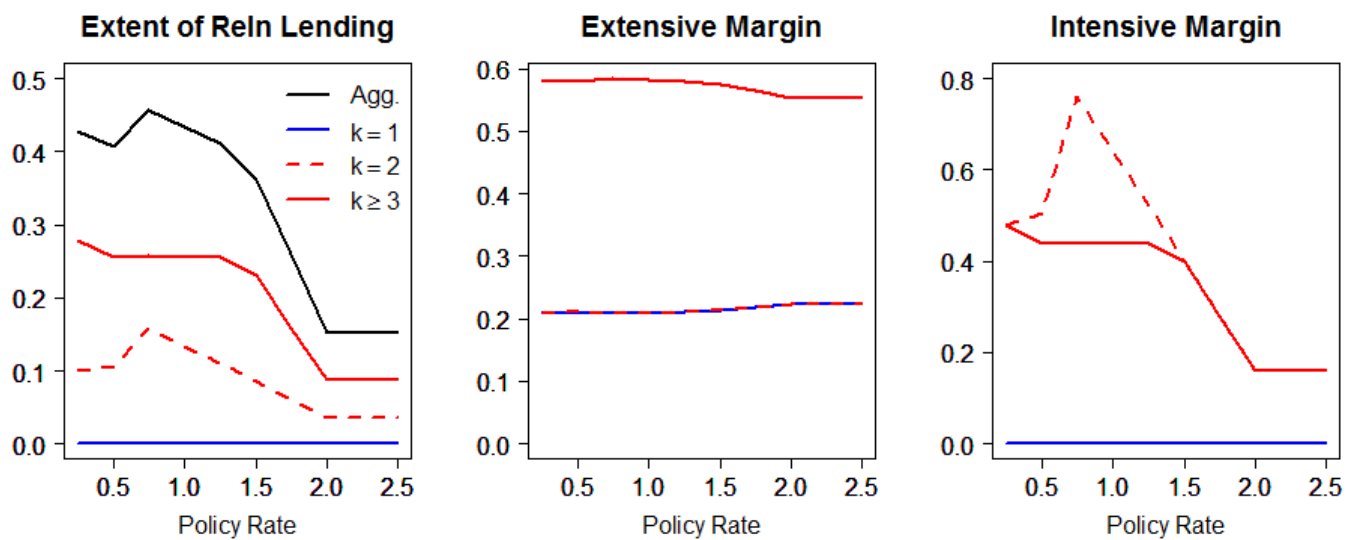
Relationship Lending and the Transmission of Monetary Policy

Figure S.2: Dynamics in the extended model

(a) Transition between steady states, $r=0.5$ to $r=0.75$
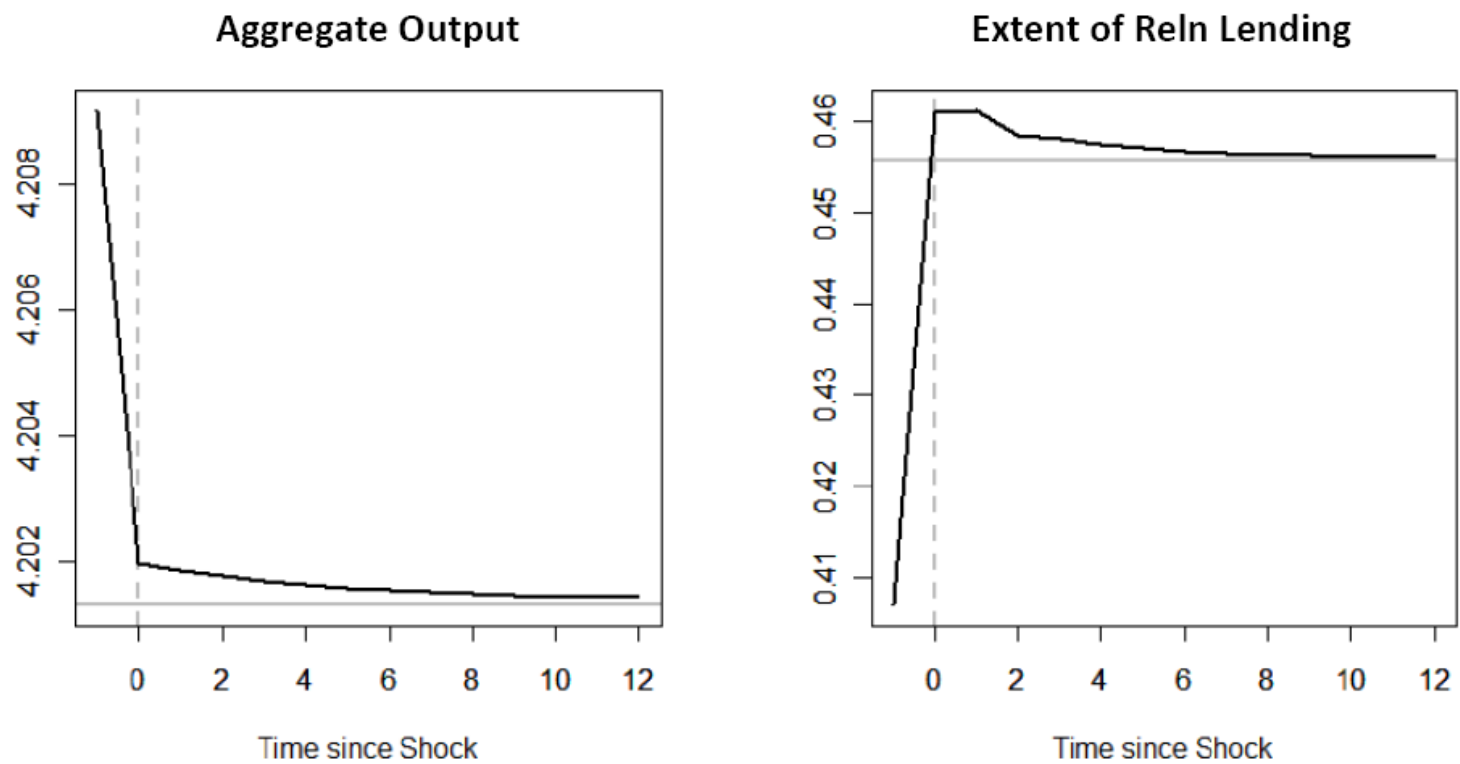

(b) Transition between steady states, $r=0.75$ to $r=1$

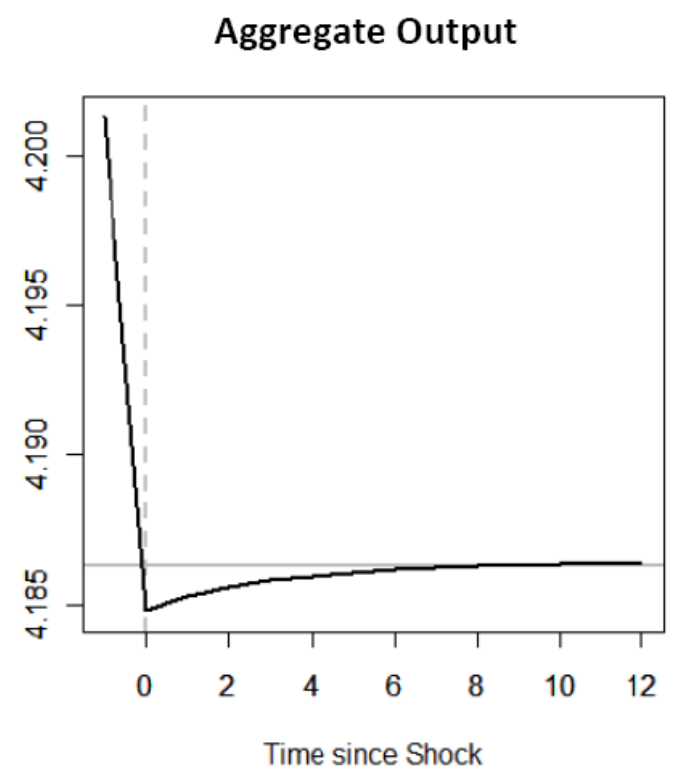

Extent of Reln Lending

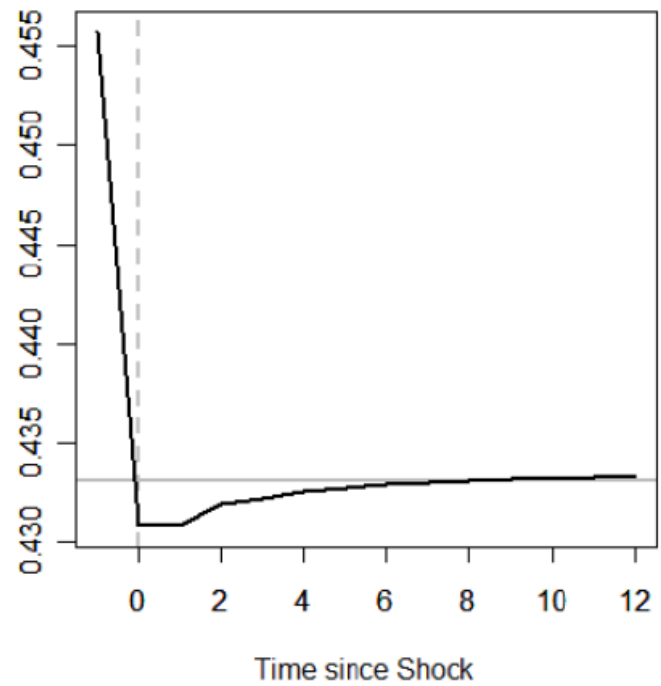

